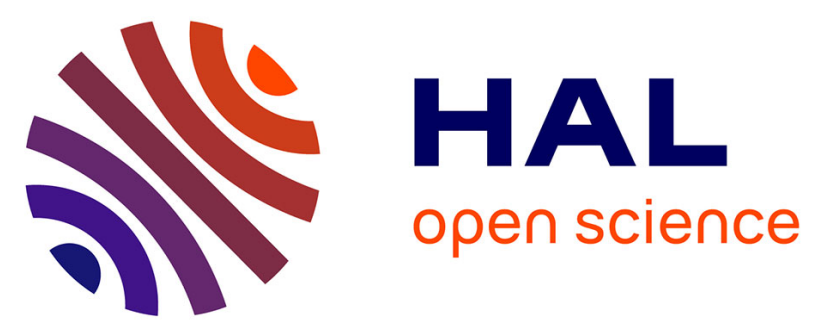

\title{
Large-Scale Synthesis of Helicene-Like Molecules for the Design of Enantiopure Thin Films with Strong Chiroptical Activity
}

Amina Bensalah-Ledoux, Delphine Pitrat, Thibault Reynaldo, Monika Srebro-Hooper, Barry Moore, Jochen Autschbach, Jeanne Crassous, Stéphan Guy, Laure Guy

\section{To cite this version:}

Amina Bensalah-Ledoux, Delphine Pitrat, Thibault Reynaldo, Monika Srebro-Hooper, Barry Moore, et al.. Large-Scale Synthesis of Helicene-Like Molecules for the Design of Enantiopure Thin Films with Strong Chiroptical Activity. Chemistry - A European Journal, 2016, 22 (10), pp.3333-3346. 10.1002/chem.201504174. hal-01260351

\section{HAL Id: hal-01260351}

\section{https://hal-univ-rennes1.archives-ouvertes.fr/hal-01260351}

Submitted on 2 Jun 2016

HAL is a multi-disciplinary open access archive for the deposit and dissemination of scientific research documents, whether they are published or not. The documents may come from teaching and research institutions in France or abroad, or from public or private research centers.
L'archive ouverte pluridisciplinaire $\mathbf{H A L}$, est destinée au dépôt et à la diffusion de documents scientifiques de niveau recherche, publiés ou non, émanant des établissements d'enseignement et de recherche français ou étrangers, des laboratoires publics ou privés. 


\title{
Large-scale synthesis of helicene-like molecules for the design of enantiopure thin films with strong chiroptical activity
}

\author{
Amina Bensalah-Ledoux ${ }^{1}$, Delphine Pitrat ${ }^{2}$, Thibault \\ Reynaldo $^{3}$, Monika Srebro-Hooper*4 ${ }^{* 4}$ Barry Moore II $^{5}$, Jochen \\ Autschbach $^{5}$, Jeanne Crassous ${ }^{* 3}$, Stephan Guy ${ }^{1}$, and Laure \\ Guy*2 $^{* 2}$ \\ 1 ILM Université Lyon 1, CNRS UMR5306, Villeurbanne F-69622, France \\ ${ }^{2}$ Université de Lyon, CNRS, École Normale Supérieure de Lyon, UMR 5182, 46, Allée d'Italie, \\ 69364 Lyon cedex 07, France \\ ${ }^{3}$ Institut des Sciences Chimiques de Rennes, UMR 6226 Campus de Beaulieu, CNRS-Université de \\ Rennes 135042 Rennes Cedex, France \\ ${ }^{4}$ Department of Theoretical Chemistry, Faculty of Chemistry, Jagiellonian University, R. Ingardena 3 , \\ 30-060 Krakow, Poland \\ ${ }^{5}$ Department of Chemistry, University at Buffalo, State University of New York, Buffalo, NY \\ 14260-3000, USA
}

\section{Introduction}

Organic molecular materials offer attractive alternatives to inorganics for optoelectronic applications due to their low cost, flexibility, and possibility to easily modify their properties

*Corresponding authors: srebro@chemia.uj.edu.p, jeanne.crassous@univ-rennes1.fr, laure.guy@ens-lyon.fr 
through an insertion of functional groups by chemical synthesis. Molecules belonging to the family of helicenes have been attracting a great interest especially during the last fifteen years when a lot of publications demonstrated their uncommon properties. ${ }^{[1-3]}$ Our attention is mainly drawn on the exceptional chiroptical activities provided by a helical scaffold that recently gave rise to very interesting potential applications in the field of organic electronics, ${ }^{[4-10]}$ and chiroptical switches. ${ }^{[1-15]}$

Nevertheless, main issues still appear when going from a molecule to a functional material: the access to large quantities of active molecules and the often difficult device fabrication. In this paper, we report our strategies to overcome those difficulties.

Firstly, we propose a synthetic route that yields gram scale of enantiopure dibenzo[c]acridine derivatives that are helicene-like compounds. The procedure is based on the key intermediate bis-tetralone 2 that crystallizes as a conglomerate. ${ }^{[16]}$ Indeed, among various methods for the access to enantiopure compounds, preferential crystallization of conglomerates is probably the most attractive method that fits with large-scale production and high level of enantiomeric purity.

The chiroptical properties of compounds in solution within a series have been studied by electronic circular dichroism (ECD) and vibrational circular dichroism (VCD) spectroscopies. Moreover, the corresponding quantum-chemical calculations were performed in order to understand better relationships between the molecular structure and the observed chiroptical properies.

In the last part, we investigate the potential application of these new helicene-like compounds as molecular materials of large-magnitude chiroptical properties. Pulsed laser deposition (PLD) has been used to make pure organic thin films. This technique does not require additionnal functionalization of the molecules and, providing the control of the laser energy in mild condition, it allows to grow organic chiral thin films without degradation. ${ }^{[17,18]}$ The solid-state ECD and VCD of the thin films were recorded to monitor the chirality in the films. Finally, the optical rotatory dispersion (ORD), which is the key parameter for optical devices, is measured down to $740 \mathrm{~nm}$, where no molecular absorption occurs.

\section{Results and Discussion}

\section{Helicene-like synthesis}

We have previously reported the synthesis of a new family of dibenzo[c]acridine skeleton in an optically pure form that exhibits high optical rotation (OR). ${ }^{[19]}$ This scaffold offers several 
possibilities of structural modifications that allow the optimization of the structure in order to reach as high OR as possible. Although the synthetic pathway was easily scalable on multigram scale in the racemic series, the resolution was the limiting step for the large-scale access to pure enantiomers.

Here, we present a new and very efficient pathway able to yield the targeted helical dibenzo[c]acridine molecule $\mathbf{8}$ on gram scale and in enantiomeric pure form. The first step is an Ullmann's homocoupling of tetralone $\mathbf{1}$, followed by the enlargement of the chromophore unit by a Friedlaender reaction to yield 4 or 6 (Figure 1).

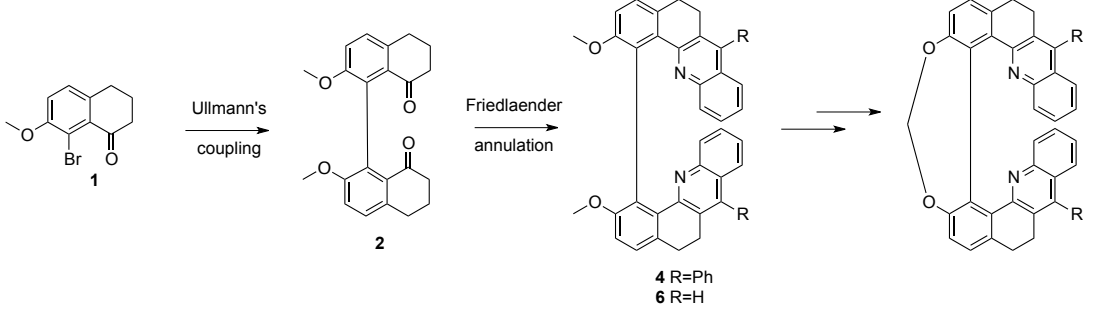

Figure 1: New synthetic pathway proposed for dibenzo[c]acridine-type helicenic molecules.

In the racemic version, using a procedure previously described, ${ }^{[19]} \mathbf{2}$ is converted in the compound 4 with $94 \%$ yield by a double Friedlaender reaction with the aminobenzophenone hydrochloryde 3. A more constrained helicene-like structure $\mathbf{5}$ is easily accessible after quantitative demethoxylation and formation of methylene bridged derivative with $95 \%$ yield. The remarkable advantage of this pathway is that the axially chiral bis-tetralone $\mathbf{2}$ belongs to the family of the conglomerates and its resolution by preferential crystallization has recently been optimized. ${ }^{[20]}$ Even if we faced a case, complicated by a multiepitaxy phenomenon, we extensively studied the productivity of its resolution that finally reached $70 \mathrm{~g}$ of enantiomer collected per hour and for one liter of solution. An Eyring analysis of the racemization process allowed us to determine the thermodynamical parameters of the racemization of 2 (see the Supporting Information, SI). A racemization barrier of $\Delta G=34.3 \mathrm{kcal} \cdot \mathrm{mol}^{-1}$ at $105^{\circ} \mathrm{C}$ was found and seemed compatible with the rest of the synthesis.

As shown in Figure 2, we first tried to convert (+)-2 using the best experimental conditions found for the racemic synthesis, that is with an excess of aminobenzophenone hydrochloryde for 2 days at $90^{\circ} \mathrm{C}$ under an acid catalyst. (-)-4 was then obtained with a reproducible yield of $94 \%$ but with a low enantiomeric excess (ee) of $60 \%$ measured by chiral HPLC using a Chiralpak IC stationary phase (for more details see the SI). Suspecting the reaction temperature to be the racemization cause, the same reaction was conducted at $70^{\circ} \mathrm{C}$. In these conditions, the enantiopurity of (-)-4 is $96 \%$ but the conversion was only $35 \%$. 


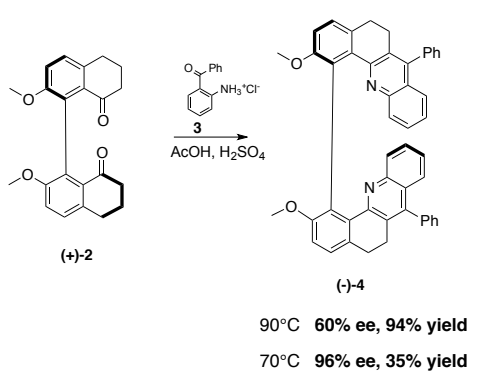

Figure 2: Enantiopurity of (-)-4 obtained by Friedlaender reaction between aminobenzophenone hydrochloryde and $(+)-2$.

In order to maintain a good conversion at a temperature lower than $90^{\circ} \mathrm{C}$, we examined several mild conditions reported for the synthesis of quinolines. A few examples have been reported in which the Friedlaender reaction is catalyzed by Lewis instead of Brönsted acids with excellent yields at room temperature. ${ }^{[21]}$ Molecular iodine $(1 \mathrm{~mol} \%)$ has also been described as a new catalyst for this reaction. ${ }^{[22]}$ Those conditions applied for the reaction between the racemic bis-tetralone $( \pm)-2$ and the hydrochloride aminobenzophenone gave, however, no conversion in favor of $( \pm)-4$. Additionally, L-proline has been recently demonstrated to act efficiently as an enamine organocatalyst in the Friedlaender synthesis of achiral quinoline, ${ }^{[23]}$ and has also been used in the desymmetrization of 4-substituted cyclohexanones at low temperature with the relatively electron-poor 3,5-dibromoaminobenzaldehyde. ${ }^{[24]}$ Again, unfortunately, no reaction occured when we reacted 3,5-dibromoaminobenzaldehyde either with $( \pm)$-2 or with the less hindered tetralone 1.

Only one annulation reaction was found to give the expected dibenzo[c]acridine skeleton from the bis-tetralone $( \pm)-2$ in mild conditions. This reaction is the transition-metal-free Meerwein-Ponndorf-Verley reaction between 2-aminobenzyl alcohol and tetralone exemplified by Martinez and collaborators. ${ }^{[25]}$ It converts efficiently bis-tetralone $( \pm)$-2 into $( \pm)-6$ and more interestingly, no loss of enantiopurity is measured by chiral HPLC when the reaction is run with $(+)-2$. The rest of the synthetic pathway shown in Figure 3 gives the bridged helicene-like compound $\mathbf{8}$. As expected, $\mathbf{6}$ is configurationally more stable than its precursor 2 with racemization barrier of $\Delta G=39.6 \mathrm{kcal} \cdot \mathrm{mol}^{-1}$ at $200^{\circ} \mathrm{C}$ (see SI). It justifies that 8 was isolated in enantiomerically pure form.

In order to study further the influence of a molecular structure on chiroptical properties, it was interesting to add the compound 9 to the series. As already reported, transformation of tetrahydrohexahelicene to hexahelicene is not obvious ${ }^{[26]}$ and we faced the same difficulties to oxidize 8. The use of palladium on charcoal under severe conditions was avoided regard- 
ing the risk of racemisation. Several attempts were undertaken: oxidation with manganese dioxide, and with trityl cation generated in situ from triphenylmethanolin trifluoroacetic acid were totally ineffective, leaving the starting material unreacted. Only reaction of 8 with 2,3dichloro-5,6-dicyano-1,4-benzoquinone (DDQ) afforded 9 with a very low yield but in an enantiomerically pure form if $(+)-\mathbf{8}$ was used as starting material.
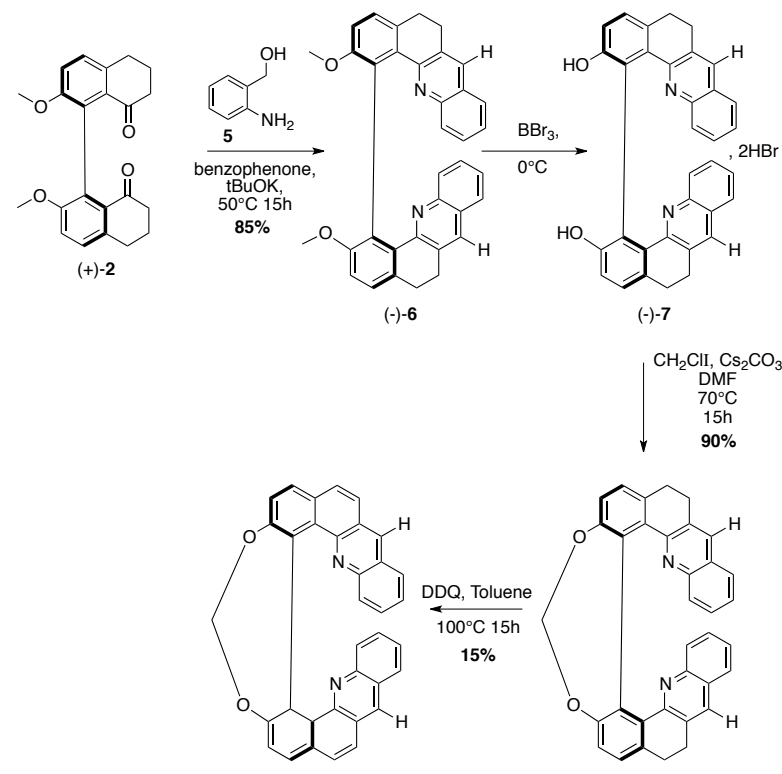

$(-)-9$

Figure 3: Synthetic access to enantiopure dibenzo[c]acridine-type helicenic molecules.

\section{Solid-state structures elucidation}

Single crystals suitable for X-ray diffraction studies of $( \pm)-\mathbf{2},( \pm)-\mathbf{6},(-)-8,( \pm)-9$ were obtained. Except for racemic $( \pm)-\mathbf{2}$, racemic $( \pm)-6$ and $( \pm)-9$ crystallize in centrosymmetric space groups, exhibiting no spontaneous resolution. Table 1 highlights that compounds in this series present an important tendency to fold into a helical shape at the solid state, even if the structure is not forced by a bridge like in the case of the compound $\mathbf{6}$. The variations in conformations are characterized by the change in the biphenyl torsional angle $\theta$ which varies from to 90 to $48^{\circ}$ through the series. The angle between the two chromophores $\phi$ spread from $23.5^{\circ}$ to $79.5^{\circ}$ and the distance $d$ between them ranges from 3.9 to $5.9 \AA$. As expected the methylene bridge in $\mathbf{8}$ induces a dramatic contraction of the helical conformation. A comparison of the bis- $\mathrm{OCH}_{3}$ structure 6 and $\mathrm{O}-\mathrm{CH}_{2}-\mathrm{O}$ bridged 8 shows a decrease of $\theta$ from $84^{\circ}$ to $48^{\circ}$. The two quinoyl subunits in $\mathbf{8}$ are clearly closer than in $\mathbf{6}$ with an inter-chromophores distance of 


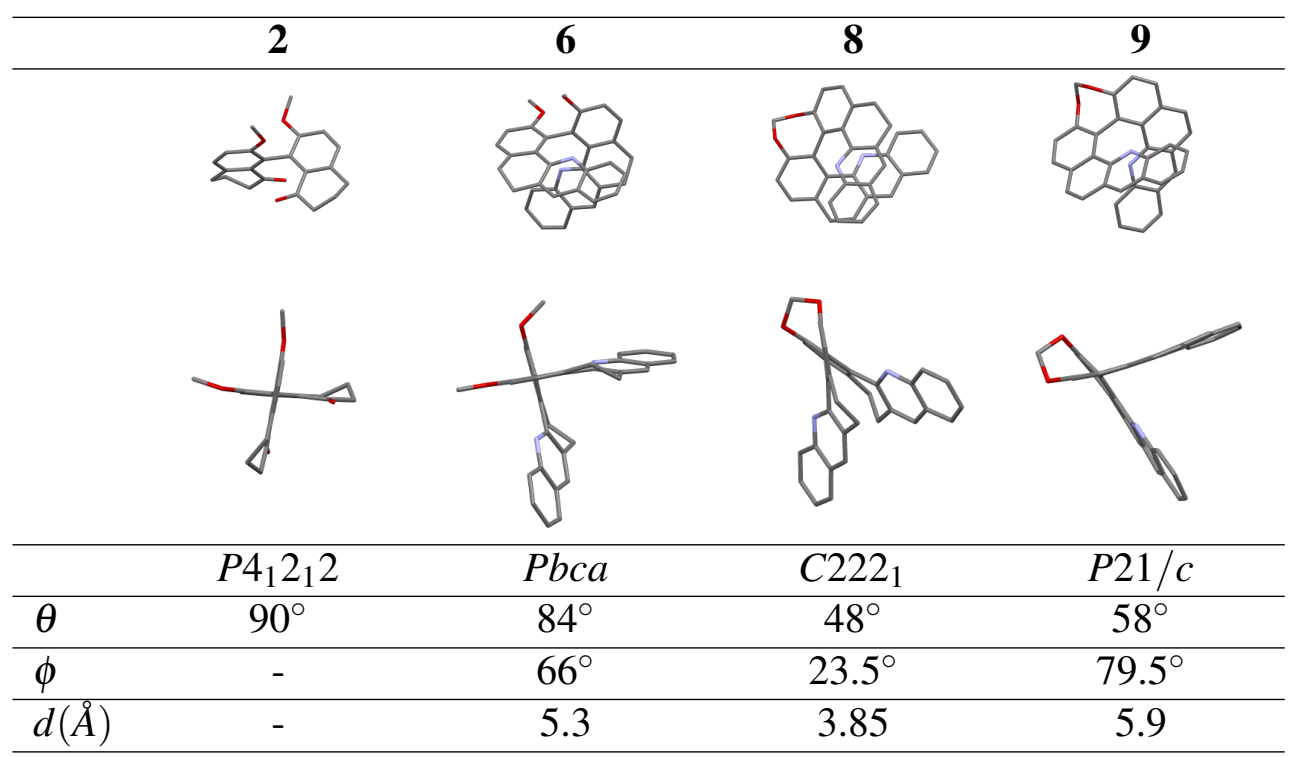

Table 1: X-ray crystal structures of $( \pm)-\mathbf{2},( \pm)-\mathbf{6},(-)-8$ and $( \pm)-9$ which show face and side elevations (hydrogen atoms are omitted for clarity; red $\mathrm{O}$; blue $\mathrm{N}$ ). $\theta$ : Biphenyl torsion angle. $\phi$ : Angle between the two quinoyls' planes of each benzo[c]acridine subunit. $d$ : Distance between the two pyridine rings' centroid of each benzo[c]acridine subunit.

$3.9 \AA$ and they are almost parallel with an angle between the two quinoyls' planes of $23.5^{\circ}$ instead of $66^{\circ}$ for the open structure 6. Another important change in the conformation results from the oxidation of $\mathbf{8}$ into 9. The methylene bridge is present in both molecules and ensures a small torsion angle but it is $10^{\circ}$ larger for 9 than for $\mathbf{8}$. The optimal interaction between the two chromophores observed in 8 allowed by the flexibility of the 5,6-dihydrobenzo[c]acridine motif is not maintained in the fully aromatized skeleton of 9. As a consequence, the interchromophores distance $(5.9 \AA)$ and the angle between the two quinoyls' planes $\left(79.5^{\circ}\right)$ are the highest within the series.

\section{Optical Rotation (OR) and Electronic Circular Dichroism (ECD) studies}

The enantiopurity of samples (-)-6, $(+)-6,(-)-8,(+)-8$ and $(+)-9$ was confirmed by chiral HPLC or by ${ }^{1} \mathrm{H}$ NMR using D-camphorsulfonic acid as chiral derivating agent (SI). The optical activities are reported in Table 2 as specific optical rotation $[\alpha]_{D}\left(10^{-1 \circ} \mathrm{g}^{-1} \mathrm{~cm}^{2}\right)$ and the corresponding molar optical rotation values $[\Phi]_{D}\left(10^{-3 \circ} \mathrm{mol}^{-1} \mathrm{~cm}^{2}\right)$ that better quantify the activity at a molecular level. The molar rotation (MR) of the bridged system $\mathbf{8}$ is nearly doubled as compared to the non-bridged 6. Almost the same increase in the $[\Phi]_{D}$ is observed as a consequence of the oxidation when going from (+)-8 to (+)-9. Interestingly, the OR for 


\begin{tabular}{lccc}
\hline & $(+)-6$ & $(+)-8$ & $(+)-9$ \\
\hline Expt. & & & \\
{$[\alpha]_{D}$} & +830 & +1705 & +2684 \\
{$[\Phi]_{D}$} & +4316 & +8593 & +13420 \\
\hline Calc. & & & \\
{$[\Phi]_{D}$} & +4369 & +6009 & +13557 \\
\hline
\end{tabular}

Table 2: Experimental specific optical rotation $\left([\alpha]_{D}\right.$, in $\left.10^{-1 \circ} \mathrm{g}^{-1} \mathrm{~cm}^{2}\right)$ and molar optical rotation $\left([\Phi]_{D}\right.$, in $\left.10^{-3 \circ} \mathrm{mol}^{-1} \mathrm{~cm}^{2}\right)$ measured in $\mathrm{CH}_{2} \mathrm{Cl}_{2}$ solutions. $[\Phi]_{D}$ calculated with $\mathrm{LC}-\mathrm{PBE} 0 * / \mathrm{SV}(\mathrm{P})$ with continuum solvent model for $\mathrm{CH}_{2} \mathrm{Cl}_{2}$.

$\mathbf{6}$ and $\mathbf{8}$ are comparable to those previously reported for molecules having the same skeleton but bearing a phenyl substituent instead of an hydrogen on the pyridine rings, ${ }^{[19]}$ which may indicate that optical activity in such compounds is predominantly due to a helical scaffold.

The corresponding UV-visible and ECD spectra measured in acetonitrile are shown in Figure 4. They are dominated by strong bands in the UV region $(\lambda<400 \mathrm{~nm})$, and, as expected, enantiomers give mirror-image spectra. The molecules with positive $[\alpha]_{D}$ possess positive sign of the longest-wavelength $\mathrm{CD}$ band and vice versa. The absorption cutoff located around $370 \mathrm{~nm}$ for $\mathbf{6}$ and $\mathbf{8}$ takes place at $430 \mathrm{~nm}$ for $\mathbf{9}$. The longest-wavelength ECD bands are between 350 and $390 \mathrm{~nm}$ for $\mathbf{6}$ and 8, and extends up to $440 \mathrm{~nm}$ for $\mathbf{9}$ which is reflected in the increased OR values of $\mathbf{9}$ as compared to $\mathbf{6}$ and $\mathbf{8}$. Interestingly, the longest-wavelength ECD band of $\mathbf{8}$ is in the vanishing tail of the longest-wavelength absorption band. Thus, compared to the unbridged $\mathbf{6}$, the chiroptical properties of $\mathbf{8}$ are increased without any loss in the transparency of the molecule, which is the key parameter for optical material design.

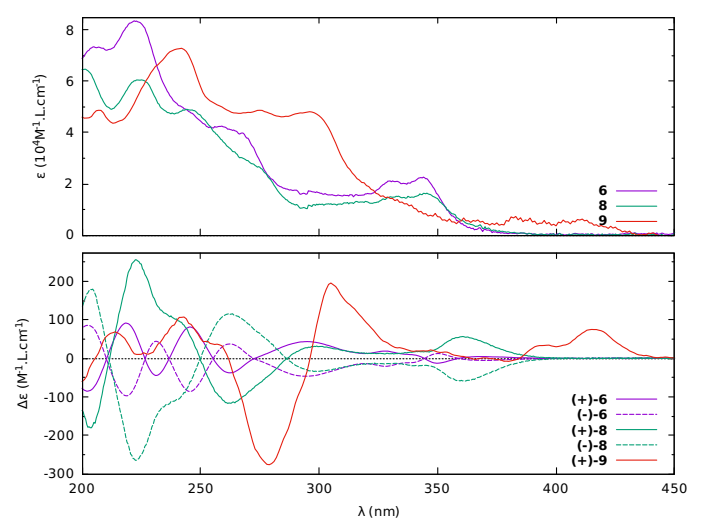

Figure 4: UV-visible (upper panel) and CD (lower panel) spectra for $\mathbf{6 , 8}$, and $\mathbf{9}$ in acetonitrile.

A detailed theoretical study on chiroptical properties of $\mathbf{6 , 8}, \mathbf{8}$ and $\mathbf{9}$ was carried out and 

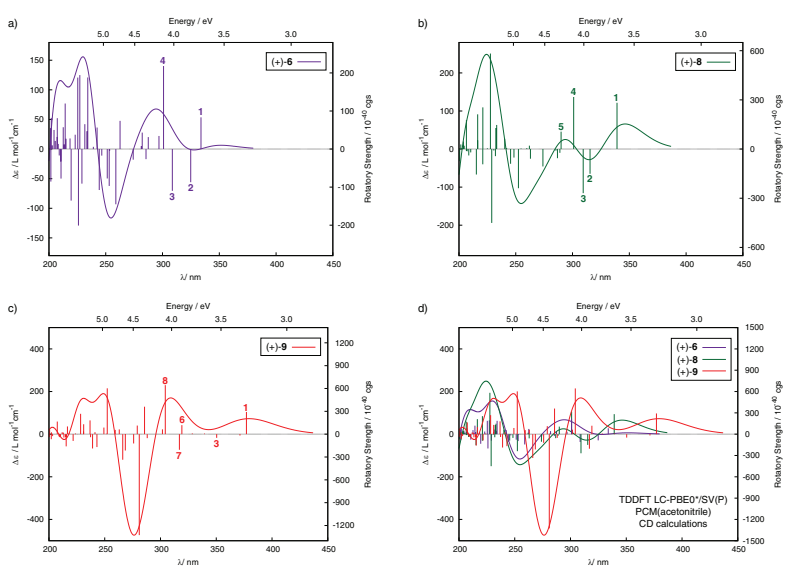

Figure 5: Comparison of the simulated CD spectra of $(+)-6,(+)-8$, and (+)-9. A color scheme corresponds to the experimental data in Figure 4. No spectral shifts were applied. Calculated excitation energies and rotatory strengths indicated as 'stick' spectra. Numbered excitations correspond to those analyzed in detail (see the SI).

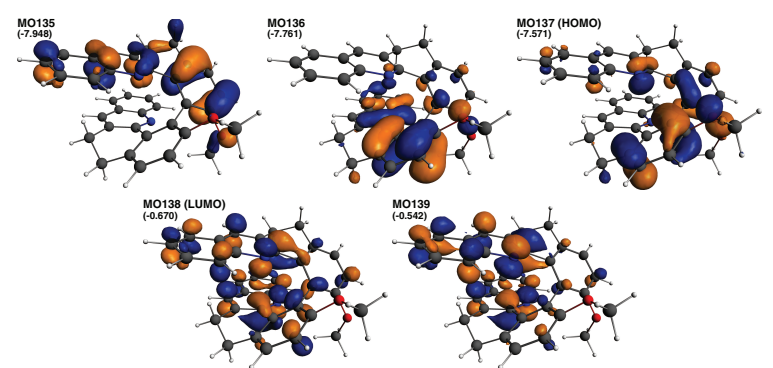

Figure 6: Isosurfaces (0.04 au) of MOs involved in selected transitions of 6. LC-PBE0*/SV(P) solvent calculations. In parentheses: Orbital energies in $\mathrm{eV}$.

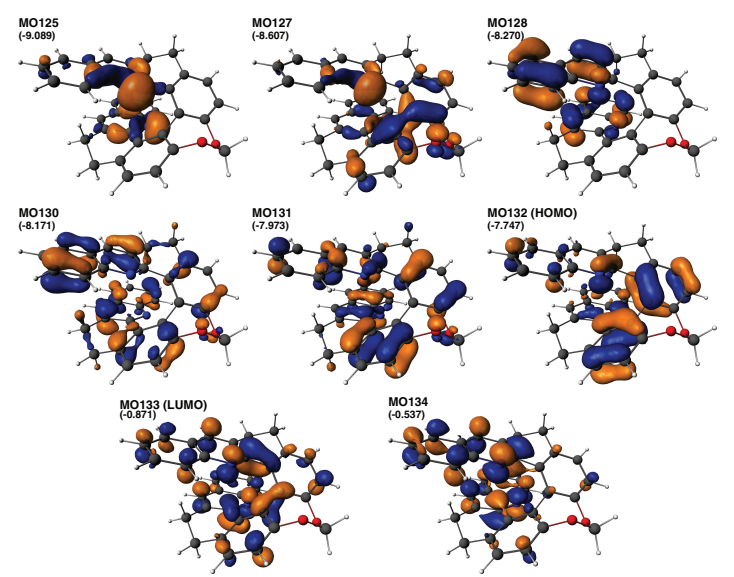

Figure 7: Isosurfaces (0.04 au) of MOs involved in selected transitions of 8. LC-PBE0*/SV(P) solvent calculations. In parentheses: Orbital energies in $\mathrm{eV}$. 


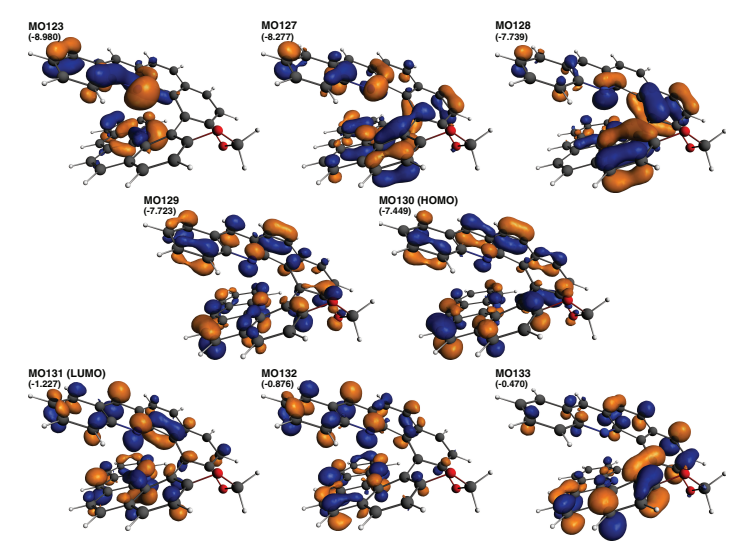

Figure 8: Isosurfaces (0.04 au) of MOs involved in selected transitions of 9. LC-PBE0*/SV(P) solvent calculations. In parentheses: Orbital energies in $\mathrm{eV}$.

a full set of data, along with an analysis, can be found in the Supporting Information. Descriptions of the computational methods used for the calculations of chiroptical properties can be found in References 27 and 28. The computational protocol of BP DFT geometry optimizations followed by BHLYP TDDFT response calculation (BHLYP/BP) was previously established to be fairly well suited for describing the chiroptical properties of a diverse set of organic and organometallic helicene systems. ${ }^{[14,29-34]}$ However, more recently we have also shown that functionals with range-separated exchange and correct asymptotic behavior (longrange correction, LC) as well as use of geometries optimized with dispersion corrections may yield significant improvements. ${ }^{[35-40]}$ Indeed, as described in the SI, the use of an LC-PBE0* parametrization with an optimally-tuned range-separation parameter $\gamma^{*}{ }^{[36]}$ in the TDDFT calculations for dispersion-corrected molecular structures seems to be indispensable to provide a good agreement of simulated CD spectra with experiment for the systems studied.

The calculated (LC-PBE0*/SV(P)//BLYP-D3/TZVP with continuum solvent model) OR values and ECD spectra for (+)-6, (+)-8, and (+)-9 are presented in Table 2 and Figure 5 , respectively. Selected labeled excitations in the low- and medium-energy regions of the $\mathrm{CD}$ spectra have been analyzed in detail. A list of occupied-to-unoccupied MO pairs that are involved in the selected excitations with $10 \%$ or more weight is provided in the SI. The corresponding MOs are visualized in Figures 6, 7, and 8 for $\mathbf{6 , 8}$, and 9, respectively.

Calculated ORs (Table 2) agree well with the experiment although for $\mathbf{8}$ visible underestimation occurs (vide infra). As seen in Figure 5, the main spectral features of the experiment, i.e. sign patterns, relative energetic positions, and the intensities of particular CD bands, are also overall correctly reproduced by the calculations. In the case of $\mathbf{8}$ some overestimation of negative intensity around $325 \mathrm{~nm}$ is observed (vide infra), but the relative intensities of the first 
and second positive CD bands in the low-energy part of the spectrum matches the experiment well. The frontier molecular orbitals calculated for both $\mathbf{6}$ and $\mathbf{8}$ appear to be very similar (Figures 6 and 7) despite evident differences in molecular structures of both compounds. The LUMOs are almost evenly spread out over the whole molecule, whereas the HOMOs are predominantly localized on the $\pi$-systems in the center parts of the molecular structures. Presumably as a result of rigidification of the system, in the case of $\mathbf{8}$ the HOMO has also significant contributions on the terminal aromatic rings. On the other hand, the HOMO of 6 clearly involves a lone-pair of the $-\mathrm{OCH}_{3}$ oxygen. Interestingly, the rigidification hardly affects orbital energies of corresponding MOs. As expected, MOs characteristics change for the fully aromatized system 9. In this case, the HOMO corresponds to an almost evenly spread out $\pi$-electron system, which is typically observed for $\pi$-conjugated helicene backbones. Although the spatial distribution of the LUMO in $\mathbf{9}$ resembles those calculated for $\mathbf{6}$ and $\mathbf{8}$, its energetic level becomes visibly stabilized upon aromatization. The similar stabilizing effect, however less pronounced, is also observed for other unoccupied MOs of 9.

In accordance with experiment, (+)-6 displays consecutively positive and negative CD bands of very weak inensity in the lower-energy part of the spectrum. The former (positive) is dominated by the excitation $\mathrm{n}^{\circ} 1$ calculated at $E=3.71 \mathrm{eV}(334 \mathrm{~nm})$ involving HOMOto-LUMO (MO137-to-MO138: 63\%) and HOMO-1-to-LUMO (MO136-to-MO138: 10\%) character. It therefore corresponds to a $\pi$-to- $\pi *$ transition with some charge-transfer (CT) as it involves orbitals centered in different parts of $\pi$-electron system. The negative band is due to excitation $\mathrm{n}^{\circ} 2$ calculated at $E=3.82 \mathrm{eV}(325 \mathrm{~nm})$. It has two main contributions from HOMO and HOMO-1 to LUMO+1 (MO137-to-MO139: 39\% and MO136-to-MO139: 17\%) and reveals a similar assignment as excitation $\mathrm{n}^{\circ} 1$. The next excitation, $\mathrm{n}^{\circ} 3(E=4.02 \mathrm{eV}, 309 \mathrm{~nm})$, has also negative rotatory strength, but it is canceled by excitation $\mathrm{n}^{\circ} 4(E=4.12 \mathrm{eV}, 301 \mathrm{~nm})$ which affords a strong positive rotatory strength and is accordingly responsible for the broad positive $\mathrm{CD}$ intensity in the medium-energy spectral range. This excitation involves transitions from HOMO-2 to LUMO and LUMO+1 (MO135-to-MO138: 31\%, MO135-to-MO139: $24 \%$ ) and reveals a clear CT character.

The assignment of the CD spectrum of $(+)-8$ is similar to $(+)-6$. The first positive intense $\mathrm{CD}$ band originates from excitation $\mathrm{n}^{\circ} 1$ calculated at $E=3.66 \mathrm{eV}(339 \mathrm{~nm})$ that is an almost pure HOMO-to-LUMO $\pi$-to- $\pi *$ transition (MO132-to-MO133: 84\%). The origin of the lowest-energy (longest-wavelength) ECD bands appears to be thus the same for both $\mathbf{6}$ and 8. Upon rigidification of the system a significant increase in its HOMO-LUMO character is however observed which may be responsible for an increase in its intensity. This leads in consequence to nearly double molar rotation for $\mathbf{8}$ as compared to $\mathbf{6}$. The next two excitations 
of $(+)-8, \mathrm{n}^{\circ} 2(E=3.93 \mathrm{eV}, 315 \mathrm{~nm})$ and $\mathrm{n}^{\circ} 3(E=4.01 \mathrm{eV}, 309 \mathrm{~nm})$, reveal strong negative rotatory strengths, which are only partially suppressed by a strong positive rotatory strength of excitation $\mathrm{n}^{\circ} 4$ calculated at $E=4.12 \mathrm{eV}(301 \mathrm{~nm})$. Consequently, somewhat overestimated negative $\mathrm{CD}$ intensity is calculated in $(+)-\mathbf{8}$ around $4.25 \mathrm{eV}$, which may explain underestimation of the calculated OR (Table 2). The second positive CD band experimentally observed for $(+)-8$ between 4.0 and $4.5 \mathrm{eV}$ is dominated by the excitations $\mathrm{n}^{\circ} 4$ and by $\mathrm{n}^{\circ} 5(E=4.28$ $\mathrm{eV}, 290 \mathrm{~nm}$ ). The main contribution to the former is from HOMO-2 to LUMO (MO130-toMO133: 45\%), while the latter is dominated by HOMO-5-to-LUMO+1 (MO127-to-MO134: 27\%) and HOMO-7-to-LUMO (MO125-to-MO133: 26\%) transitions. They can be assigned as $\pi$-to- $\pi^{*}$ transitions with a partial CT character.

In line with the experiment, calculated CD spectrum of (+)-9 is significantly red-shifted compared to $(+)-6$ and (+)-8. The longest-wavelength positive CD band in $\mathbf{9}$ is again found to be dominated by the excitation $\mathrm{n}^{\circ} 1(E=3.29 \mathrm{eV}, 377 \mathrm{~nm})$ that has mostly HOMO-to-LUMO $\pi$-to- $\pi *$ character (MO130-to-MO131: 76\%) enhanced by CT-like HOMO-2-to-LUMO $\pi$-to$\pi^{*}$ transition (MO128-to-MO131: 13\%). As inspection of the orbital energies revealed (vide supra) aromatization has a strongly stabilizing effect on the LUMO of 9 and to a much lesser degree on the HOMO, reducing the HOMO-LUMO gap which may rationalize the very large bathochromic shift of low-energy $\mathrm{CD}$ band upon oxidation of $\mathbf{8}$. The next intense excitation, $\mathrm{n}^{\circ} 3(E=3.54 \mathrm{eV}, 350 \mathrm{~nm})$, has a negative rotatory strenght and in consequence it is responsible for a visible decrease in ECD intensity in agreement with experiment. The second, mediumenergy, positive band of the ECD spectrum of $(+)-9$ is dominated by three excitations, $\mathrm{n}^{\circ} 6$ $(E=3.88 \mathrm{eV}, 319 \mathrm{~nm})$ and $\mathrm{n}^{\circ} 8(E=4.07 \mathrm{eV}, 304 \mathrm{~nm})$ of positive rotatory strengths that are partially cancelled by $\mathrm{n}^{\circ} 7(E=3.91 \mathrm{eV}, 317 \mathrm{~nm})$ imposing negative intensity. The excitations correspond mostly to $\pi$-to- $\pi *$ transitions within the $\pi$-conjugated electron system (see the SI).

\section{Vibrational Circular Dichroism spectra}

Vibrational Circular Dichroism (VCD) spectroscopy ${ }^{[41-43]}$ of organic helicenes has been used by different research groups in order to examine their general characteristic VCD fingerprints, ${ }^{[44-47]}$ to determine their absolute configuration, ${ }^{[48-51]}$ or to evaluate different theoretical models. ${ }^{[52,53]}$ The experimental IR and VCD spectra of enantiopure $(+)$ and $(-)$ organic helicene-like molecules $\mathbf{6}$ and $\mathbf{8}$ have been measured in $\mathrm{CD}_{2} \mathrm{Cl}_{2}$ and are depicted in Figure 9. Molecules 6 and 8 display similar IR fingerprints in the 1400-1520, 1225-1325 and 1025$1100 \mathrm{~cm}^{-1}$ regions. As for the VCD spectra, they likewise demonstrate a clear and strong VCD fingerprint between $1400-1520 \mathrm{~cm}^{-1}$ while the other two spectral regions display a set of several VCD bands that appear strong for the bridged compound $\mathbf{8}$ but of weak intensity for 

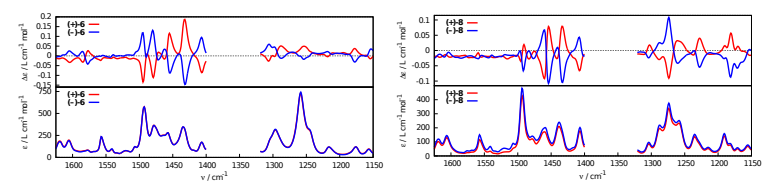

Figure 9: Experimental IR and VCD spectra of ( $(-)$ - and (+)-6 and of $(-)$ - and (+)-8 measured in $\mathrm{CD}_{2} \mathrm{Cl}_{2}$ in the $1025-1625 \mathrm{~cm}^{-1}$ region. The domain where the solvent absorbs has been removed.

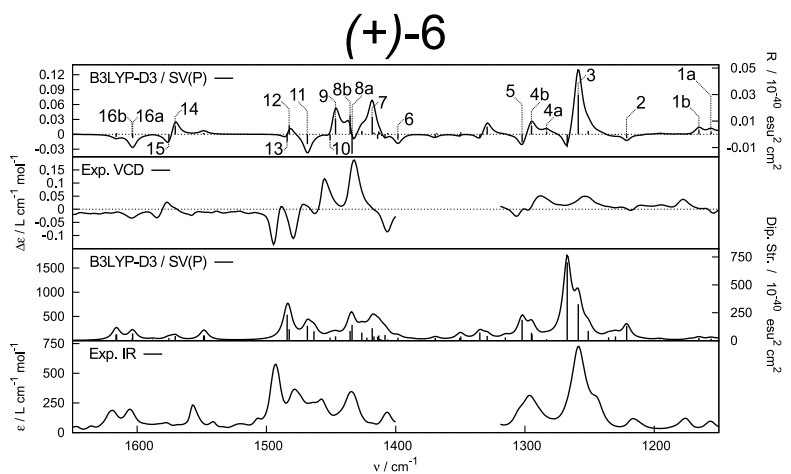

Figure 10: Comparison of experimental and calculated (B3LYP-D3/SV(P) gas phase, frequencies scaled by 0.9614$)$ IR and VCD spectra of $(+)-6$. Numbered VCD vibrations correspond to those analyzed in detail (Table 3, Figure 12).

open non-bridged 6.

To facilitate the interpretation of the experimental data, the IR and VCD spectra were calculated for both $\mathbf{6}$ and $\mathbf{8}$, and a detailed analysis of selected VCD-active vibrations was performed.

Comparisons of calculated and experimental IR and VCD spectra are shown in Figures 10 and 11 for $\mathbf{6}$ and $\mathbf{8}$, respectively. Additionally, the frequencies of the selected (numbered) VCD-active vibrations, scaled frequencies, and rotatory strengths are collected in Tables 3 and 4. The corresponding atomic displacements are shown in Figures 12 and 13. A detailed assignment of these vibrations is given in the SI.

The calculated IR spectra of $\mathbf{6}$ and $\mathbf{8}$ reproduce the experimental ones well (Figures 10 and 11, respectively), both for the vibrational frequencies (after scaling by 0.9614) and for the intensities. For biaryl-type molecule $(+)-6$, the intense IR bands seen experimentally around $1260 \mathrm{~cm}^{-1}$ are well reproduced by theory and correspond to symmetric bending of the $-\mathrm{CH}_{3}$ groups coupled with several in- and out-of-phase - $\mathrm{CCH}$ bending displacements (see for example vibration $\mathrm{n}^{\circ} 3$ ). While these modes afford a clear VCD signature in the calculated spectrum they appear rather weak in the experimental one. This is probably due to the flexibility of 6 in solution especially regarding the $-\mathrm{OCH}_{3}$ groups. The experimental VCD pattern of $(+)-6$ in 


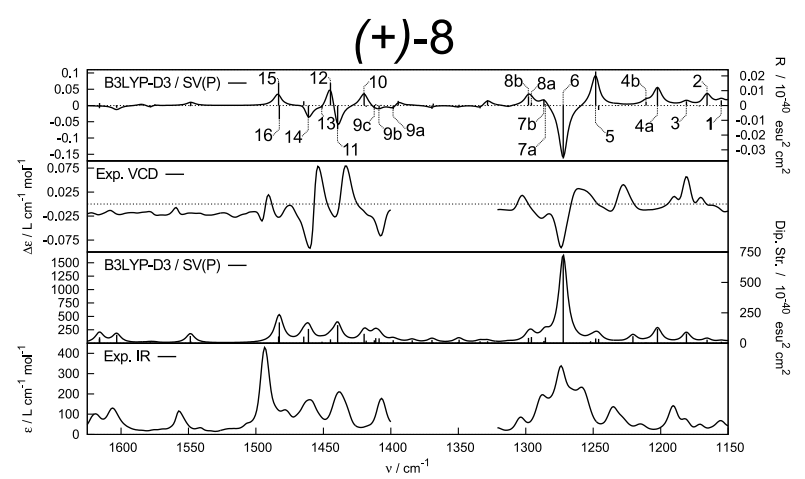

Figure 11: Comparison of experimental and calculated (B3LYP-D3/SV(P) gas phase, frequencies scaled by 0.9614$)$ IR and VCD spectra of $(+)-8$. Numbered VCD vibrations correspond to those analyzed in detail (Table 4, Figure 13).

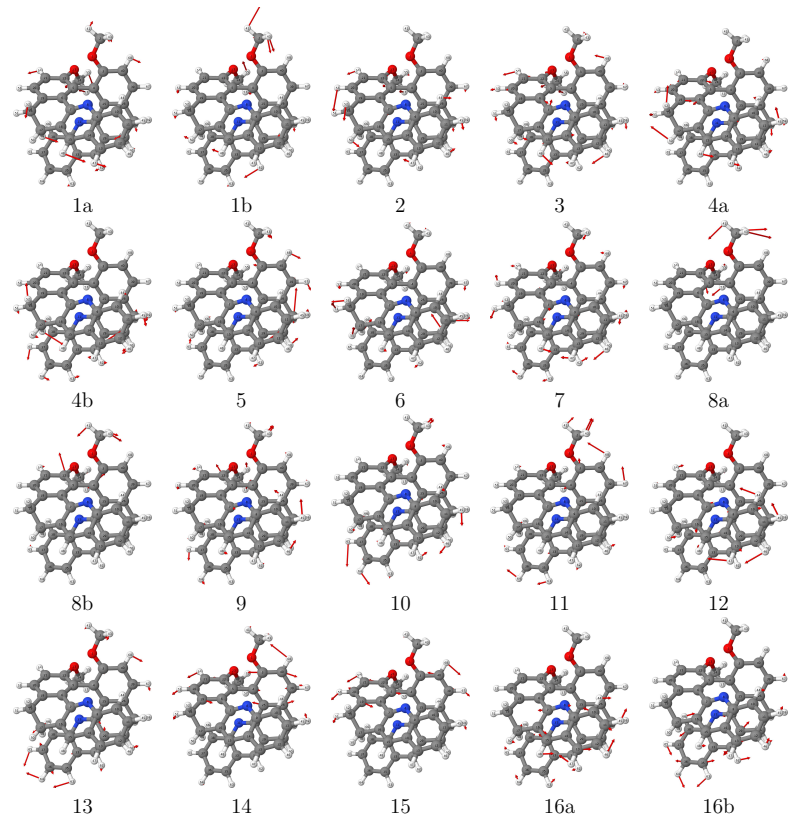

Figure 12: Selected vibrational displacements for modes in (+)-6 listed in Table 3.

the $1400-1500 \mathrm{~cm}^{-1}$ region is reasonably well reproduced by the calculation. For example, the positive VCD bands at 1430 and $1460 \mathrm{~cm}^{-1}$ seem to correspond to the calculated $\mathrm{n}^{\circ} 7$ and $\mathrm{n}^{\circ} 9$ which represent symmetric bending motions of the $-\mathrm{CH}_{3}$ coupled with in- and out-of-phase -CCH bending vibrations in both benzo[c] acridine-type moieties. Similarly, the negative VCD band at $1480 \mathrm{~cm}^{-1}$ agrees well with the calculated vibration $\mathrm{n}^{\circ} 11$ which corresponds to the $-\mathrm{CH}_{3}$ in-phase symmetric bends and to a set of coupled in-phase - $\mathrm{CCH}$ bends. Overall, these vibrations appear to be dominated by strongly coupled $-\mathrm{CCH}$ and $-\mathrm{CH}_{3}$ bending modes. Finally, the C-C stretches are found in the calculated vibrational modes $n^{\circ} 14-16 \mathrm{~b}$ and assigned 


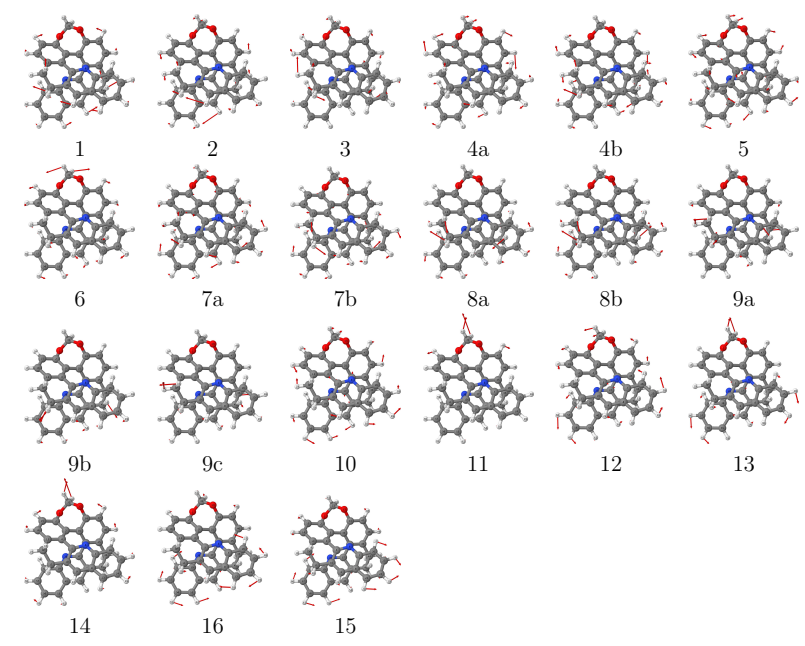

Figure 13: Selected vibrational displacements for modes in (+)-8 listed in Table 4.

Table 3: Selected B3LYP-D3/SV(P) vibrational frequency and rotatory strength values of $(+)$ 6. Compare with Figure 10.

\begin{tabular}{lccc} 
& \multicolumn{3}{c}{$(+)-6$} \\
Peak & $\tilde{v} / \mathrm{cm}^{-1}$ & $\tilde{v}$ (scaled) $/ \mathrm{cm}^{-1}$ & $R / 10^{-44} \mathrm{cgs}$ \\
\hline $1 \mathrm{a}$ & 1202 & 1156 & 22 \\
$1 \mathrm{~b}$ & 1212 & 1165 & 32 \\
2 & 1270 & 1221 & -30 \\
3 & 1309 & 1259 & 299 \\
$4 \mathrm{a}$ & 1335 & 1283 & 19 \\
$4 \mathrm{~b}$ & 1347 & 1295 & 62 \\
5 & 1355 & 1302 & -60 \\
6 & 1454 & 1398 & -39 \\
7 & 1475 & 1418 & 130 \\
$8 \mathrm{a}$ & 1491 & 1434 & -146 \\
$8 \mathrm{~b}$ & 1493 & 1435 & 144 \\
9 & 1505 & 1447 & 116 \\
10 & 1509 & 1451 & -43 \\
11 & 1527 & 1468 & -74 \\
12 & 1542 & 1482 & 69 \\
13 & 1544 & 1484 & -55 \\
14 & 1634 & 1571 & 61 \\
15 & 1639 & 1576 & -47 \\
$16 \mathrm{a}$ & 1668 & 1603 & -28 \\
$16 \mathrm{~b}$ & 1668 & 1604 & -18
\end{tabular}

to the positive, negative, negative sequence in the experimental VCD spectrum at 1577,1586 , and $1607 \mathrm{~cm}^{-1}$ respectively. The C-C stretches are also strongly coupled with -CCH bend- 
Table 4: Selected B3LYP-D3/SV(P) vibrational frequency and rotatory strength values of $(+)$ 8. Compare with Figure 11.

\begin{tabular}{lccc} 
& \multicolumn{3}{c}{$(+)-8$} \\
Peak & $\tilde{v} / \mathrm{cm}^{-1}$ & $\tilde{v}$ (scaled) $/ \mathrm{cm}^{-1}$ & $R / 10^{-44} \mathrm{cgs}$ \\
\hline 1 & 1201 & 1155 & 35 \\
2 & 1212 & 1166 & 81 \\
3 & 1228 & 1181 & 28 \\
$4 \mathrm{a}$ & 1251 & 1202 & 122 \\
$4 \mathrm{~b}$ & 1259 & 1211 & 25 \\
5 & 1298 & 1248 & 230 \\
6 & 1323 & 1272 & -358 \\
$7 \mathrm{a}$ & 1337 & 1285 & 8 \\
$7 \mathrm{~b}$ & 1338 & 1287 & 41 \\
$8 \mathrm{a}$ & 1348 & 1296 & 19 \\
$8 \mathrm{~b}$ & 1350 & 1298 & 62 \\
$9 \mathrm{a}$ & 1454 & 1398 & -27 \\
$9 \mathrm{~b}$ & 1465 & 1409 & -24 \\
$9 \mathrm{c}$ & 1469 & 1412 & -21 \\
10 & 1477 & 1420 & 85 \\
11 & 1497 & 1439 & -161 \\
12 & 1503 & 1445 & 152 \\
13 & 1509 & 1451 & -21 \\
14 & 1520 & 1461 & -85 \\
16 & 1542 & 1483 & -93 \\
15 & 1543 & 1483 & 156
\end{tabular}

ing modes and reminiscent of pure helicenes. Note that the saturated $-\mathrm{CH}_{2}-\mathrm{CH}_{2}-$ moieties of non-aromatic cycles participate as well via coupling to vibrations involving the $-\mathrm{CH}$ moieties.

The bridged helicene-like molecule (+)-8 displays a set of positive VCD bands between 1160 and $1260 \mathrm{~cm}^{-1}$ in the experimental spectrum, which agree well with the calculated vibrations $n^{\circ} 1-5$. For example, the calculated vibrational mode $n^{\circ} 5$ most likely corresponds to the experimental VCD signal at $1260 \mathrm{~cm}^{-1}$ and is caused by a wagging motion of the bridging $-\mathrm{CH}_{2}$ - and out-of-phase - $\mathrm{CH}$ bending displacements in the two benzo[c]acridine-type moieties. The strong negative VCD band at $1273 \mathrm{~cm}^{-1}$ corresponds to the calculated vibration $\mathrm{n}^{\circ} 6$ which combines a twisting motion of the bridging $-\mathrm{CH}_{2}$ - group with low-amplitude outof-phase $-\mathrm{CH}$ bending motions in the two benzo[c] acridine-type fragments. The 1400-1500 $\mathrm{cm}^{-1}$ region displays overall a similar VCD fingerprint as for (+)-6 and agrees well with the calculated spectrum, with the same progression of positive and negative VCD bands. We 
assign the positive VCD bands at 1425 and $1455 \mathrm{~cm}^{-1}$ to the calculated vibrational modes $\mathrm{n}^{\circ} 10$ and $\mathrm{n}^{\circ} 12$ which combine a wagging motion of the bridging $-\mathrm{CH}_{2}$ - moiety with doublets and triplets of in-phase - $\mathrm{CH}$ bending motions extending over the helical backbone. The VCD band at $1441 \mathrm{~cm}^{-1}$ may be assigned to calculated $\mathrm{n}^{\circ} 11$ which represents a scissoring motion of the bridging $-\mathrm{CH}_{2}$ - coupled to out-of-phase - $\mathrm{CH}$ bending modes. The calculated frequencies of peaks $\mathrm{n}^{\circ} 15-16$ are very similar; in the experimental VCD there is a negative-positive feature in the $1500-1475 \mathrm{~cm}^{-1}$ region which is assigned to the calculated vibrational modes $\mathrm{n}^{\circ} 16$ and $\mathrm{n}^{\circ} 15$, respectively. The $\mathrm{C}-\mathrm{C}$ stretching region above $1500 \mathrm{~cm}^{-1}$ revealed weak VCD intensities and could not be assigned. Note that similar to molecule $\mathbf{6}$, the saturated $-\mathrm{CH}_{2}-\mathrm{CH}_{2}-$ moieties of non-aromatic cycles participate in the VCD-active vibrations and are strongly coupled to the $-\mathrm{CH}$ vibrational motions.

\section{From molecules to materials}

Previously, helicenes have been incorporated in materials and main reports deal with optoelectronic devices such as polarized light-emitting diodes or transistors. For these studies, the films are made by either doping a polymer matrix ${ }^{[6]}$ or by electrodeposition of a thiophene functionnalized helicene ${ }^{[54]}$. Here, the purpose to design such helicene like chiral molecules is to build new optical devices such as chirowaveguides. ${ }^{[55]}$ By using Pulsed Laser Deposition PLD, we envisioned to make pure organic films. This technique have been previously used to grow isotropic highly chiral thin films of several bridged binaphtyl compounds. ${ }^{[17]}$ The PLD technique benefits from the fact that it is instantaneous by nature. All the heated material is ejected from the substrate and is quickly (faster than the racemization time) cooled down on the substrate. Finally, by controlling the laser fluence, PLD allows access to chiral thin films with high optical rotation. This technique is once more exemplified in this work with the helicene-like molecules 8 . The ablating laser with a fluence of $2 \mathrm{~m} \cdot \mathrm{J} \cdot \mathrm{cm}^{-2}$, focused on the target, removes some material that is collected on the substrate located a few centimeter away from the target (more details are given in the SI).

We checked that no molecular degradation occurred by comparing NMR spectra of redisolved films to those of the starting molecules. Depending on the deposition times, films from $90 \mathrm{~nm}$ up to $1500 \mathrm{~nm}$ were successfully grown on different substrates for VCD, ECD and ORD characterization. Refractive index $\left(n_{D}=1.75\right)$ and thickness were measured by the "M-line" technique. In all these measurements the probe optical beam crosses the sample perpendicularly to the surface. No difference were detected by rotating the samples around the optical axis or by inverting the face of the material which is a strong indication of isotropic structura- 
tion in the growing plane. ${ }^{[56]}$ All the obtained films present a very good quality, neither cracks nor microscopic defects are observed. Figure 14 presents the atomic force microscopy (AFM) images $(1 \mathrm{X} 1 \mu \mathrm{m})$ of a $500 \mathrm{~nm}$ thick helicene like thin film, deposited at $20 \mathrm{~m} \cdot \mathrm{J} \cdot \mathrm{cm}^{-2}$.T he films surface is very smooth with a roughness of about $2 \mathrm{~nm}$.

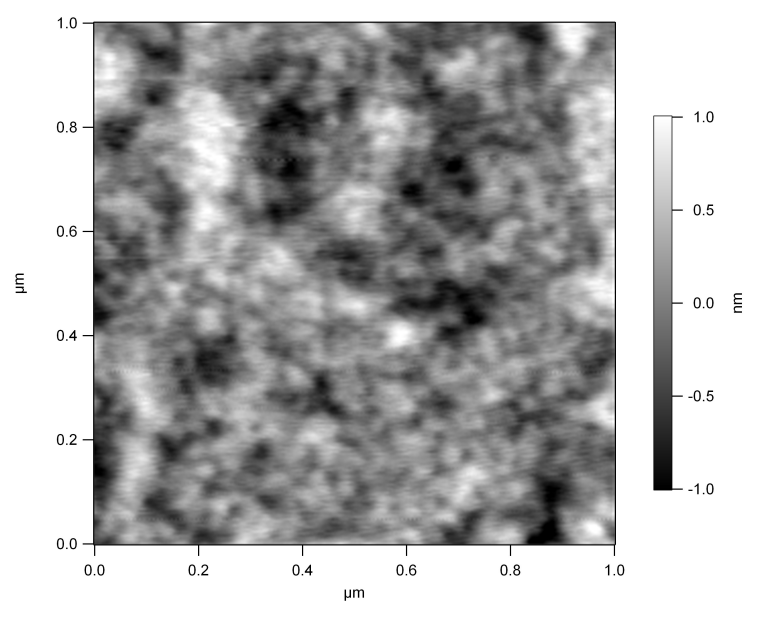

Figure 14: AFM image of the helicene films surface deposited by PLD

The UV-vis absorption and ECD spectra of $( \pm)-8$ in solution and in the solid-state are displayed in Figure 15. For a better comparison of the solution-state and the solid-state spectra, the same scaling factor has been applied to the solution $\varepsilon$ and $\Delta \varepsilon$ spectra in order to match the maximum absorption intensity in both states. Solution- and solid-state absorption spectra are very similar except that the bands in the solid-state are uniformly red-shifted by about $5 \mathrm{~nm}$ compared to solution ones. The main difference in the ECD spectra is the enhancement of the bands intensity in the long-wavelength part of the spectrum by a factor of about 2 in favor of the solid state.

However, the strong similarity in the ECD spectra for both states - in particular the fact that all the ECD bands are present in the solid state and no new one appears - strongly suggests that solid-state ECD spectra essentially originate from the intramolecular interactions of single molecules rather than intermolecular interactions between neighbouring molecules in the crystal. Moreover, the scaling factor between the solution and solid-state spectra permits to estimate the concentration in the solid state via the Beer-Lambert law (i.e. assuming that the film absorbance is given by $A b s=\varepsilon \cdot c \cdot L$ where $\varepsilon$ is the specific absorbance in the solution, $c$ is the concentration in the solid state and $L=90 \mathrm{~nm}$ the sample thickness). The obtained value $c=1.4 \mathrm{~g} \cdot \mathrm{cm}^{-3}$ is very close to the density $\left(1.2 \mathrm{~g} \cdot \mathrm{cm}^{-3}\right)$ given by X-rays. This is a strong indication of the similarity between the electronic structures of molecules $\mathbf{8}$ in solution 
and in the solid state.

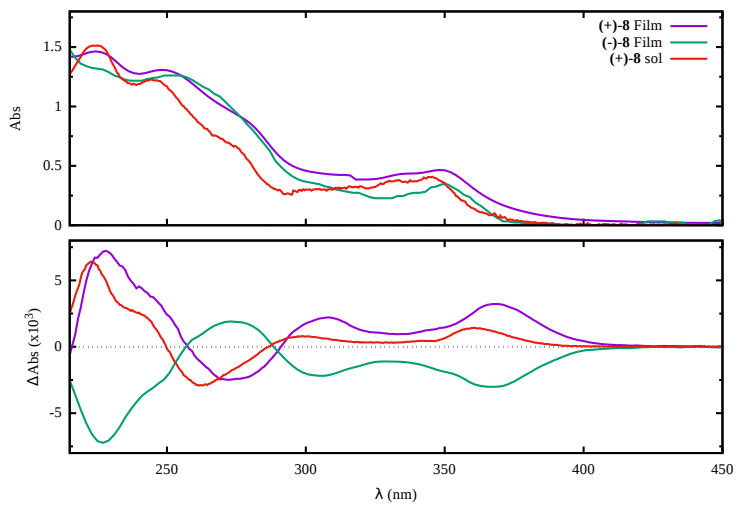

Figure 15: UV-visible (upper panel) and CD (lower panel) spectra for $\mathbf{8}$ in acetonitril and for pure $90 \mathrm{~nm}$ thin film in absorbance units. The solution spectra ( $\varepsilon$ units) are drawn with a scaling factor of $0.25 \cdot 10^{-4}$.

The clear VCD signatures of the (-)- and (+)-8 enantiomers in solution were also found with thin films deposited over silicon wafer and $\mathrm{CaF}_{2}$ respectively. The films prepared were thick enough to display a good absorbance in the IR spectrum $(\mathrm{A}=0.15-0.55)$ and clear and intense VCD signals $\left(\Delta A\right.$-values up to $\left.7.7 \cdot 10^{-5}\right)$. From Figure 16 one can see that, overall, the IR and VCD spectra in the solid state exhibit only few differences to the solution spectra. A negative band at $920 \mathrm{~cm}^{-1}$ for (-)-8 appears in the solid state but is not seen in solution due to solvent absorption. The region between $1050-1350 \mathrm{~cm}^{-1}$ displays similar bands at similar wavenumbers but with different relative intensities as compared to the liquid phase, both in IR and in VCD. For example, the negative and positive VCD bands at 1260 and $1273 \mathrm{~cm}^{-1}$, respectively, which were previously assigned to calculated vibrational modes $\mathrm{n}^{\circ} 5$ and 6 (vide supra), are less intense relative to the ones between $1125-1250 \mathrm{~cm}^{-1}$ that have become stronger. The same characteristic features are found for the $1400-1500 \mathrm{~cm}^{-1}$ region. The rigidification and the conformational changes of the molecular system that occur in the solid state may account for the changes in the relative intensities. Note that, as mentionned above, the films were found to be isotropic, thus displaying no birefringence ${ }^{[57]}$. This is also illustrated by the fact that VCD spectra with good mirror-image relationship were obtained even using different wafers (silicon and $\mathrm{CaF}_{2}$ ). Finally, these results illustrate not only how VCD spectroscopy can give information about the integrity of the chiral molecule in the solid state (despite the fact that it was strongly heated upon laser ablation), but also how the IR and VCD bands intensities are modified, i.e. how the dipole and rotatory strengths vary from the liquid to the solid state. 

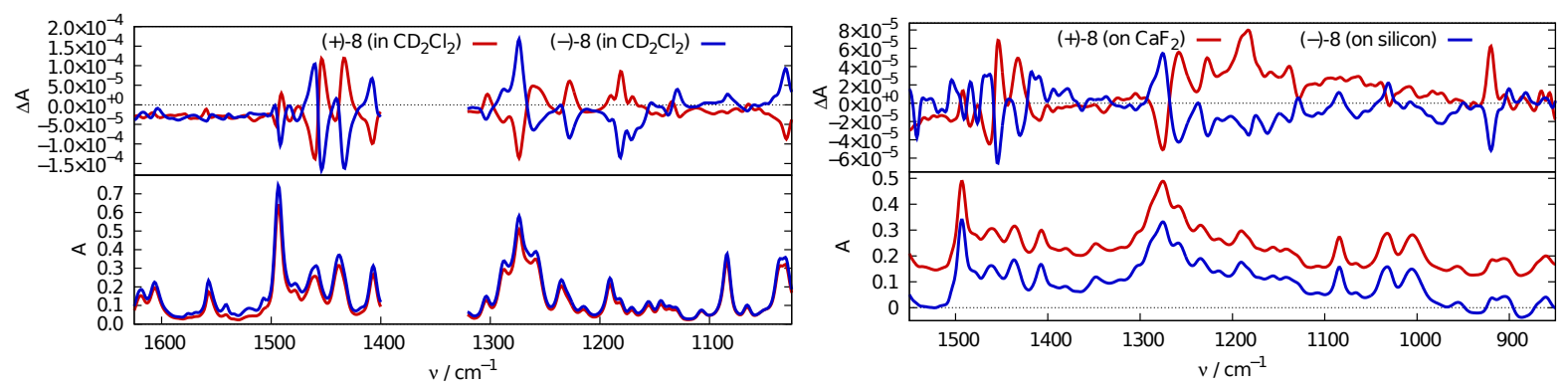

Figure 16: Comparison of experimental IR and VCD spectra of (-)- and (+)-8 measured in $\mathrm{CD}_{2} \mathrm{Cl}_{2}$ solution and in thin films.

Figure 17 reports the ORD spectra of (-)- and (+)-8 thin films corrected by the films thickness. As expected, at a given wavelength, the rotatory power is positive or negative depending on the stereochemistry of the starting molecule. Regular wavelength dependence of OR, related to the absorption bands of the molecule, is obtained. Optical rotation measured

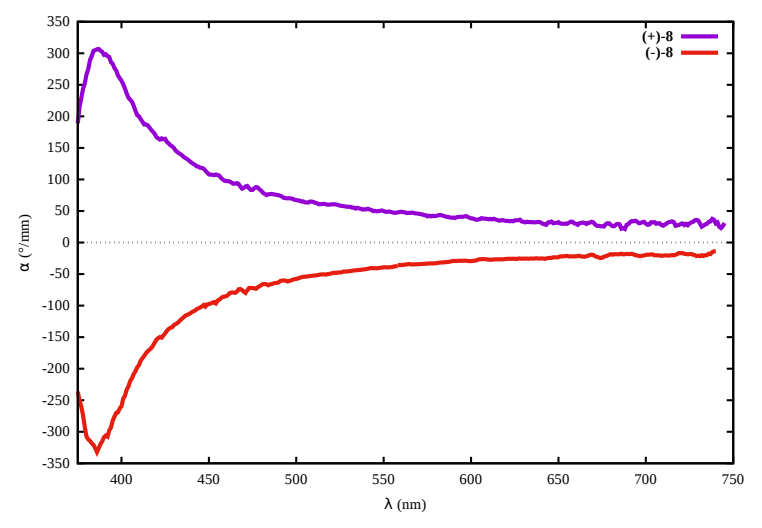

Figure 17: Solid-state optical rotatory dispersion of $(-)-8$ and (+)-8 thin films. Measurements were recorded with a monochromator of $2 \mathrm{~nm}$ linewidth.

in the thin film of $(+)-8$ is $\alpha_{D}$ (solid) $=30 \pm 5^{\circ} \mathrm{mm}^{-1}$. The error mainly comes from the thickness inhomogeneity. Comparing the optical rotation in the solid state and in solution (Table 2) based on the Biot law, we were able to estimate the $\mathbf{8}$ thin film concentration. The value obtained is $c=1.3 \mathrm{~g} \cdot \mathrm{cm}^{-3}$ (after taking into account the refractive index correction factor $\left(n_{D} \text { (solid) } / n_{D} \text { (solution) }\right)^{[58]}$, again very close to the density given by crystallographic $\mathrm{X}$-ray measurements $\left(1.2 \mathrm{~g} \cdot \mathrm{cm}^{-3}\right)$. The chiroptical specific values are thus similar in solution and in the solid state which confirms that the molecular structure of $\mathbf{8}$ is maintained during the deposition process.

In order to evaluate the ability of $\mathbf{8}$ to become a good chiral optical material for waveguiding 
applications, the OR needs to be measured in a transparent spectral region. The solution is transparent at wavelength above $400 \mathrm{~nm}$, but in the solid state, due to the huge concentration, acceptable transparency occurs at higher wavelengths. For binaphtyl molecular material we have measured the propagation losses in waveguides versus wavelength and found that a gap of $250 \mathrm{~nm}$ is required to ensure a lack of molecular absorption. ${ }^{[59]}$ Taking the same precaution for the helicene-like molecule $\mathbf{8}$, this molecular material can be used at wavelength longer than $650 \mathrm{~nm}$. The ORD curves presented in Figure 17 clearly show that the OR at this wavelength is still significant, $\alpha(\lambda=650 \mathrm{~nm})=27 \pm 5^{\circ} \mathrm{mm}^{-1}$ for $(+)-8$. At the highest wavelength of our experimental set-up $(\lambda=740 \mathrm{~nm})$, we have measured a rotatory power of $20 \pm 5^{\circ} \mathrm{mm}^{-1}$ which makes this system a very promising candidate for chirowaveguides in the near infrared region.

\section{Conclusions}

Because it belongs to the conglomerates, bis-tetralone $\mathbf{2}$ is efficiently resolved by preferential crystallization and is the key intermediate in the synthesis of a new series of enantiopure helicene-like molecules $\mathbf{6}, \mathbf{8}$, and $\mathbf{9}$ on gram scale. The compounds exhibit large-magnitude optical rotations and intense ECD spectra. The corresponding first-principles calculations agree overall well with experiment and provide additional insight into structure-chiroptical property relationships, in particular effects of rigidification and aromatization of the molecular structure. The (-) and (+) enantiomers of $\mathbf{6}$ and $\mathbf{8}$ display clear and strong VCD signatures that can be assigned with the help of DFT calculations. They reveal similar vibrational modes except for the fingerprints originating from the presence of the methoxy groups in $\mathbf{6}$ or of the bridging methylene in $\mathbf{8}$. Interestingly, the strong coupling of the $-\mathrm{CH}_{2}-\mathrm{CH}_{2}$ - groups present in the non-aromatic cycles strongly contributes to the VCD pattern.

The systems are further demonstrated to be good candidate materials for chiroptical devices.

The helicene-like system 8 easily gives thin films by using the pulsed laser deposition technique. Based on the ECD and VCD measurements in solution and in the solid state, the integrity of $\mathbf{8}$ in the deposited films was confirmed.

Comparison of VCD of $\mathbf{8}$ and $\mathbf{8}$ 's films demonstrates remarkable sensitivity of this technique to any changes of the molecular system that occur due to physical change of state (solution to solid state). Finally, those films have remarkable optical activities in the near IR $\alpha(\lambda=740$ $\mathrm{nm})=20 \pm 5^{\circ} \mathrm{mm}^{-1}$ and their application as chirowaveguides is under study. 


\section{Experimental Section}

\subsection{General}

All experiments were conducted under normal atmospheric conditions. Experiments under micro-waves are run with a Biotage Initiator 2.5 microwave synthesizer. ${ }^{1} \mathrm{H}$ and ${ }^{13} \mathrm{C}$ NMR spectra were recorded at $500.10352 \mathrm{MHz}$ and $125.76408 \mathrm{MHz}$ respectively with a Bruker Avance II 500 spectrometer, chemical shifts are reported in ppm from $\mathrm{Me}_{4} \mathrm{Si}$ standard. Mass spectrometry (HRMS LSIMS) is performed by the Centre de Spectrométrie de Masse, University of Lyon France, on a Thermo-Finnigan MAT 95XL spectrometesolution (in ${ }^{\circ} /\left(\mathrm{dm} \cdot \mathrm{cm}^{-3} \cdot \mathrm{g}\right.$ ) were measured in a $1 \mathrm{dm}$ thermostated quartz cell on a Jasco-P1010 polarimeter. Solid-state ECD and ORD were measured using home-made spectrometers details. UV and CD spectra are recorded at IBCP Lyon France on a Chirascan spectrometer. IR and VCD spectra were recorded on a Jasco FSV-6000 spectrometer. Bis-tetralone $\mathbf{2}$ and is synthesized as previously described. ${ }^{[19]}$

CCDC-934344, CCDC-934343, CCDC-1431168, CCDC-1431194, CCDC-143122 contain the supplementary crystallographic data for this paper. These data can be obtained free of charge from The Cambridge Crystallographic Data Centre via www.ccdc.cam.ac.uk/data

\subsection{Synthetic procedures and characterization}

Compounds $\mathbf{4}$, and 5 are synthesised following procedures 4.2.1, 4.2.3, 4.2.5. Their characterizations are the same as previously described. ${ }^{[19]}$

\subsubsection{Synthesis of $( \pm)-2,2^{\prime}$-dimethoxy-5,5',6,6'-tetrahydro-1,1'-bibenzo[c]acridine $( \pm)-6$}

Under argon, bis-tetralone 2 (7 g, $20 \mathrm{mmol})$ is added to a solution of 2-amino benzyl alcohol $(7.25 \mathrm{~g}, 59 \mathrm{mmol})$ in $300 \mathrm{~mL}$ of dry THF followed by the addition of benzophenone $(10.7 \mathrm{~g}$, $59 \mathrm{mmol})$ and potassium tert-butoxyde $(7.3 \mathrm{~g}, 65 \mathrm{mmol})$. The solution is heated at $50^{\circ} \mathrm{C}$ for 15h. After cooling, THF is evaporated, replaced by $400 \mathrm{~mL}$ of $\mathrm{CH}_{2} \mathrm{Cl}_{2}$ and washed 3 times with $500 \mathrm{~mL}$ of $\mathrm{NH}_{4} \mathrm{Cl}_{\text {sat }}$ and once with $500 \mathrm{~mL}$ of solution of $\mathrm{NaOH} 1 \mathrm{M}$. After drying over $\mathrm{Na}_{2} \mathrm{SO}_{2}$, the solution is condensed under reduced pressure to give $4.54 \mathrm{~g}$ of crude product purified by chromatography over silicagel eluted with a gradient of $\mathrm{CH}_{2} \mathrm{Cl}_{2} / \mathrm{Et}_{2} \mathrm{O}$ from 100/0 to $96 / 4$ giving a beige solid $(9,97 \mathrm{~g}, 96 \%): \mathrm{mp} 207^{\circ} \mathrm{C} ;{ }^{1} \mathrm{H} \mathrm{NMR}\left(\mathrm{CDCl}_{3}, 500.10 \mathrm{MHz}\right) 7.51$ $(\mathrm{d}, J=8.18 \mathrm{~Hz}, 1 \mathrm{H}), 7.41(\mathrm{~m}, 2 \mathrm{H}), 7.32(\mathrm{~m}, 2 \mathrm{H}), 7.27(\mathrm{~d}, J=9.6 \mathrm{~Hz}, 1 \mathrm{H}), 7.18(\mathrm{~d}, J=8.26 \mathrm{~Hz}$, $1 \mathrm{H}), 3,92$ (s, 3H), $2.7(\mathrm{~m}, 2 \mathrm{H}), 2.47(\mathrm{td}, J=4.06,14.31 \mathrm{~Hz}, 1 \mathrm{H}), 1.73$ (ddd, $J=6.0,12.17$, $14.26 \mathrm{~Hz}, 1 \mathrm{H}) ;{ }^{13} \mathrm{C} \mathrm{NMR}\left(\mathrm{CDCl}_{3}, 125.76 \mathrm{MHz}\right) \delta 158.479(\mathrm{Cq}), 153.936(\mathrm{Cq}), 146.486$ 
$(\mathrm{Cq}), 133.531(\mathrm{Cq}), 133.005(\mathrm{Cq}), 132.111(\mathrm{Cq}), 131.245(\mathrm{CH}), 129.715(\mathrm{CH}), 129.314(\mathrm{Cq})$, $127.364(\mathrm{CH}), 126.525(\mathrm{Cq}), 126.331(\mathrm{CH}), 126.157(\mathrm{CH}), 125.394(\mathrm{CH}), 112.519(\mathrm{CH})$, $56.788\left(\mathrm{CH}_{3}\right), 29.207\left(\mathrm{CH}_{2}\right), 29.107\left(\mathrm{CH}_{2}\right)$; HMRS (EI): calcd: 521,2224. found: 521.2212.

\subsubsection{Synthesis of (-)-2,2'-dimethoxy-5,5',6,6'-tetrahydro-1,1'-bibenzo[c]acridine (-)-6 and $(+)-2,2^{\prime}$ '-dimethoxy-5,5',6,6'-tetrahydro-1,1'-bibenzo[c]acridine $(+)-6$}

The same procedure describded for the obtention of $( \pm)-6$ is used for the synthesis of the pure enantiomers. In a typical scale experiment, $(+)-6(1.34 \mathrm{~g}, 92 \%)$ is obtained starting from 1 $\mathrm{g}$ of (-)-2. ${ }^{1} \mathrm{H}$ NMR and ${ }^{13} \mathrm{C}$ NMR are the same than those of $( \pm)-6 .[\alpha]_{D}=-830(\mathrm{c}=0.74$, $\left.\mathrm{CH}_{2} \mathrm{Cl}_{2}\right) ;[\alpha]_{D}=+776\left(\mathrm{c}=0.55, \mathrm{CH}_{2} \mathrm{Cl}_{2}\right)$

\subsubsection{Synthesis of $( \pm)-5,5^{\prime}, 6,6^{\prime}$ 'tetrahydro-[1,1'-bibenzo[c]acridine]-2,2'-diol dihydrobromide $( \pm)-7$}

Under argon at $0^{\circ} \mathrm{C}$, to a solution $( \pm)-6(9.1 \mathrm{~g}, 17.5 \mathrm{mmol})$ in $300 \mathrm{~mL}$ of dry $\mathrm{CH}_{2} \mathrm{Cl}_{2}$ is added dropwise a solution of $\mathrm{BBr}_{3} 1 \mathrm{M}$ in $\mathrm{CH}_{2} \mathrm{Cl}_{2}(70 \mathrm{~mL}, 70 \mathrm{mmol})$. The mixture is stirred $15 \mathrm{~h}$ at room temperature then quench by dropwise addition of $\mathrm{MeOH}(5 \mathrm{~mL})$. Half of the solvent is then removed by evaporation and replaced by $400 \mathrm{~mL}$ of $\mathrm{Et}_{2} \mathrm{O}$ making $( \pm)-7,2 \mathrm{HBr}$ precipitate. The brown precipitate is filtered off and washed with $400 \mathrm{~mL}$ of $\mathrm{Et}_{2} \mathrm{O}$ and not purified further (11.35 g, 100\%) : ${ }^{1} \mathrm{H}$ NMR (DMSO, 500.10MHz) 8.745 (s, $\left.1 \mathrm{H}\right), 8.11(\mathrm{~d}, J=8.16 \mathrm{~Hz}, 1 \mathrm{H})$, $7.65(\mathrm{dd}, J=6.86,8.24 \mathrm{~Hz}, 1 \mathrm{H}), 7.57$ (ddd, $J=1.37,6.91,8.49 \mathrm{~Hz}, 1 \mathrm{H}), 7.24(\mathrm{dd}, J=8.32$, $9.72 \mathrm{~Hz}, 2 \mathrm{H}), 7.24(\mathrm{dd}, J=8.32,9.72 \mathrm{~Hz}, 1 \mathrm{H}), 3.24($ broad s, $1 \mathrm{H}), 3,01(\mathrm{~m}, 3 \mathrm{H}) ;{ }^{13} \mathrm{C} \mathrm{NMR}$ (DMSO, 125.76MHz) $\delta 153.36(\mathrm{Cq}), 153.20(\mathrm{Cq}), 140.19(\mathrm{Cq}), 136.40(\mathrm{CH}), 133.32(\mathrm{Cq})$, $132.79(\mathrm{Cq}), 131.68(\mathrm{Cq}), 131.67(\mathrm{CH}), 128.22(\mathrm{CH}), 127.99(\mathrm{CH}), 127.24(\mathrm{Cq}), 122,55(\mathrm{CH})$, $122.09(\mathrm{Cq}), 119,21(\mathrm{CH}), 27.99\left(\mathrm{CH}_{2}\right), 27.39\left(\mathrm{CH}_{2}\right)$; HMRS (EI): calcd: 493.1911 found: 493.1898.

\subsubsection{Synthesis of (-)-5,5',6,6'-tetrahydro-[1,1'-bibenzo[c]acridine]-2,2'-diol dihydrobromide (-)-7 and} (+)-5,5',6,6'-tetrahydro-[1,1'-bibenzo[c]acridine]-2,2'-diol dihydrobromide (+)-7

The same procedure describded for the obtention of $( \pm)-7$ is used for the synthesis of the pure enantiomers. In a typical scale experiment, $(+)-7,2 \mathrm{HBr}(1.9 \mathrm{~g}$, quantitative $)$ is obtained starting from $1.37 \mathrm{~g}$ of $(+)-6 .{ }^{1} \mathrm{H}$ NMR and ${ }^{13} \mathrm{C}$ NMR are the same than those of $( \pm)-6 .[\alpha]_{D}$ are not recorded due to the high absorbtion of these protonated species. 
4.2.5 Synthesis of $( \pm)-2,2^{\prime}$ '-dimethoxy-5,5',6,6'-tetrahydro-1,1'-bibenzo[c]acridine ( \pm )-8

$( \pm)-7,2 \mathrm{HBr}(11.35 \mathrm{~g}, 17.45 \mathrm{mmol})$ is placed in a Schlenck under argon in $250 \mathrm{~mL}$ of dry DMF. $\mathrm{Cs}_{2} \mathrm{CO}_{3}(10 \mathrm{~g}, 30.7 \mathrm{mmol})$ and $\mathrm{CH}_{2} \mathrm{ClI}(1.3 \mathrm{~mL}, 17.8 \mathrm{mmol})$ are added and the mixture is stirred over night at $80^{\circ} \mathrm{C}$. After cooling, DMF is removed by evaporation, replaced by $400 \mathrm{~mL} \mathrm{CH} \mathrm{CH}_{2}$ and the organic phase is washed twice by $400 \mathrm{~mL}$ of $\mathrm{H}_{2} \mathrm{O}$. After drying over $\mathrm{Na}_{2} \mathrm{SO}_{2}$, the solution is condensed under reduced pressure to give $7.5 \mathrm{~g}$ of crude product purified by chromatography over silicagel eluted with a gradient of $\mathrm{CH}_{2} \mathrm{Cl}_{2} / \mathrm{AcOEt}$ from 100/0 to 90/10 giving a $6.5 \mathrm{~g}$ beige solid which stirred in $100 \mathrm{~mL}$ of $\mathrm{CH}_{3} \mathrm{CN}$ overnight to give after filtration a white powder $(6 \mathrm{~g}, 96 \%) . \mathrm{mp} 341^{\circ} \mathrm{C} ;{ }^{1} \mathrm{H} \mathrm{NMR}\left(\mathrm{CDCl}_{3}, 500.10 \mathrm{~Hz}\right) \delta 7.47(\mathrm{~d}, J=$ $7.9 \mathrm{~Hz}, 2 \mathrm{H}), 7.43$ (d , $J=7.8 \mathrm{H}, 1 \mathrm{H}), 7.42(\mathrm{~d}, J=7.8 \mathrm{H}, 1 \mathrm{H}), 7.39-7,28(\mathrm{~m}, 6 \mathrm{H}), 7.25$ (d, $J=$ $7.68 \mathrm{~Hz}, 2 \mathrm{H}), 7,18(\mathrm{~s}, 2 \mathrm{H}), 5.68(\mathrm{~s}, 2 \mathrm{H}), 2.61(\mathrm{dd}, J=4.5,14.6 \mathrm{~Hz}, 1 \mathrm{H}), 2.60(\mathrm{dd}, J=4.5$, $14.6 \mathrm{~Hz}, 1 \mathrm{H}), 2.51(\mathrm{dd}, J=4.5,14.6 \mathrm{~Hz}, 1 \mathrm{H}), 2.48(\mathrm{dd}, J=4.5,14.6 \mathrm{~Hz}, 1 \mathrm{H}), 2.15$ (ddd, $J=$ 2.08, 4.4, $14.42 \mathrm{~Hz}, 2 \mathrm{H}), 1.35$ (t, J = $14.72 \mathrm{~Hz}, 2 \mathrm{H}), 1.34(\mathrm{t}, \mathbf{J}=14.72 \mathrm{~Hz}, 2 \mathrm{H}) ;{ }^{13} \mathrm{C} \mathrm{NMR}$ $\left(\mathrm{CDCl}_{3}, 125.76 \mathrm{MHz}\right) \delta 153.14(\mathrm{Cq}), 152.15(\mathrm{Cq}), 149.26(\mathrm{Cq}), 137.09(\mathrm{Cq}), 134.46(\mathrm{Cq})$, $132.75(\mathrm{Cq}), 131.57(\mathrm{Cq}), 131.54(\mathrm{Cq}), 129.79(\mathrm{CH}), 127.74(\mathrm{CH}), 127.38(\mathrm{CH}), 126.99(\mathrm{Cq})$, 126.39(CH), 125.75(CH), $121.72(\mathrm{CH}), 101.28\left(\mathrm{CH}_{2}\right), 28.71\left(\mathrm{CH}_{2}\right), 27.83\left(\mathrm{CH}_{2}\right) ; \mathrm{UV} /$ vis an CD (see ); HMRS (EI) [MH]+ meas : 505.1898 calcd: 505.1911.

\subsubsection{Synthesis of (-)-2,2'-dimethoxy-5,5',6,6'-tetrahydro-1,1'-bibenzo[c]acridine (-)-8 and (+)-2,2'-dimethoxy-5,5',6,6'-tetrahydro-1,1'-bibenzo[c]acridine $(+)-8$}

The same procedure describded for the obtention of $( \pm)-8$ is used for the synthesis of the pure enantiomers. In a typical scale experiment, (-)-8 $(1,3 \mathrm{~g}, 89 \%)$ is obtained starting from $1 \mathrm{~g}$ of $(+)-7 .{ }^{1} \mathrm{H}$ NMR and ${ }^{13} \mathrm{C}$ NMR are the same than those of $( \pm)-8 . \quad[\alpha]_{D}=-1705(\mathrm{c}=0.50$, $\left.\mathrm{CH}_{2} \mathrm{Cl}_{2}\right) ;[\alpha]_{D}=+1745\left(\mathrm{c}=0.5, \mathrm{CH}_{2} \mathrm{Cl}_{2}\right)$

\subsubsection{Synthesis of $( \pm)-2,2$ '-dimethoxy-1,1'-bibenzo[c]acridine ( \pm )-9}

The mixture of $( \pm)-8(0.1 \mathrm{~g}, 0.2 \mathrm{mmol})$ and DDQ $(0.1 \mathrm{~g}, 0.43 \mathrm{mmol})$ in $6 \mathrm{~mL}$ of degased toluene is refluxed over 48 hours. After cooling, the mixture is diluted in $20 \mathrm{~mL}$ of $\mathrm{CH}_{2} \mathrm{Cl}_{2}$ and washed twice by $20 \mathrm{~mL}$ of a saturated solution of $\mathrm{NaHCO}_{3}$. After drying over $\mathrm{Na}_{2} \mathrm{SO}_{2}$, the solution is condensed under reduced pressure and the crude product purified by chromatography over silicagel eluted by with $\mathrm{CH}_{2} \mathrm{Cl}_{2}$ giving a brown solid $(0.24 \mathrm{~g}, 24 \%) .{ }^{1} \mathrm{H} \mathrm{NMR}$ $\left(\mathrm{CDCl}_{3}, 500.10 \mathrm{~Hz}\right) \delta 8.09(\mathrm{~d}, J=8.31 \mathrm{~Hz}, 2 \mathrm{H}), 8.08(\mathrm{~s}, 2 \mathrm{H}), 7.79(\mathrm{~d}, J=8.93 \mathrm{~Hz}, 2 \mathrm{H}), 7.75$ $(\mathrm{d}, J=8.31 \mathrm{~Hz}, 2 \mathrm{H}), 7.52(\mathrm{~d}, J=8.18 \mathrm{~Hz}, 2 \mathrm{H}), 7.42(\mathrm{~d}, J=8.94 \mathrm{~Hz}, 2 \mathrm{H}), 7.28(\mathrm{ddd}, J=1.47$, 
6.64, 8.63 Hz, 2H ), 7.19 (ddd, $J=1.47,6.64,8.63 \mathrm{~Hz}, 2 \mathrm{H}$ ), 6.7 (d, $J=8.64 \mathrm{~Hz}, 2 \mathrm{H}$ ), 5.69 (s, $2 \mathrm{H}) ;{ }^{13} \mathrm{C} \mathrm{NMR}\left(\mathrm{CDCl}_{3}, 125.76 \mathrm{MHz}\right) \delta 133.77(\mathrm{Cq}), 133.28(\mathrm{CH}), 132.33(\mathrm{Cq}), 132.15(\mathrm{Cq})$, $129.51(\mathrm{CH}), 129.00(\mathrm{CH}), 128.28(\mathrm{CH}), 128.10(\mathrm{CH}), 126.76(\mathrm{CH}), 125.74(\mathrm{Cq}), 125.29$ $(\mathrm{CH}), 124.82(\mathrm{Cq}), 124.74(\mathrm{CH}), 122.31(\mathrm{CH}), 101.88\left(\mathrm{CH}_{2}\right)$; HMRS (EI) [MH]+ meas : 501.1581 calcd: 501.1598 .

\subsubsection{Synthesis of $(+)-2,2$ '-dimethoxy-1,1'-bibenzo[c]acridine $(+)-9$}

In a sealed vial, (+)-8 $(0.1 \mathrm{~g}, 0.2 \mathrm{mmol})$ and DDQ $(0.1 \mathrm{~g}, 0.43 \mathrm{mmol})$ are dissolved in $2 \mathrm{~mL}$ of degased toluene. The mixture is stirred over night at $100^{\circ} \mathrm{C}$. After cooling, the mixture is diluted in $15 \mathrm{~mL}$ of $\mathrm{CH}_{2} \mathrm{Cl}_{2}$ and washed twice by $20 \mathrm{~mL}$ of a saturated solution of $\mathrm{NaHCO}_{3}$. After drying over $\mathrm{Na}_{2} \mathrm{SO}_{2}$, the solution is condensed under reduced pressure and the crude product purified by chromatography over silicagel eluted by with $\mathrm{CH}_{2} \mathrm{Cl}_{2}$ giving a brown solid $(0.15 \mathrm{~g}, 15 \%) .{ }^{1} \mathrm{H}$ NMR and ${ }^{13} \mathrm{C}$ NMR are the same than those of $( \pm)-9 .[\alpha]_{D}=+2684$ (c=0.14, $\left.\mathrm{CH}_{2} \mathrm{Cl}_{2}\right)$

\section{Acknowledgments}

This work has received financial support from the National Science Foundation (CHE 1265833 to J.A.), a foreign student visitor scholarship by the University of Rennes Métropole (to B.M.), and the Foundation for Polish Science Homing Plus programme co-financed by the European Regional Development Fund under the Operational Programme Innovative Economy (to M.S.). M.S. is also grateful for financial support from the Ministry of Science and Higher Education in Poland ('Outstanding Young Scientist' scholarship). We thank the Center for Computational Research (CCR) at the University at Buffalo for computing time. J.C. acknowledges the ANR (10-BLAN-724-1-NCPCHEM). 


\section{References}

[1] N. Saleh, C. Shen, J. Crassous, Chem. Sci. 2014, 5, 3680-3694.

[2] M. Gingras, Chem. Soc. Rev. 2013, 42, 1051-1095.

[3] Y. Shen, C.-F. Chen, Chem. Rev. 2012, 112, 1463-1535, pMID: 22017405.

[4] M. Li, W. Yao, J.-D. Chen, H.-Y. Lu, Y. Zhao, C.-F. Chen, J. Mater. Chem. C 2014, 2, 8373-8380.

[5] W. Hua, Z. Liu, L. Duan, G. Dong, Y. Qiu, B. Zhang, D. Cui, X. Tao, N. Cheng, Y. Liu, RSC Adv. 2015, 5, 75-84.

[6] Y. Yang, R. C. da Costa, M. J. Fuchter, A. J. Campbell, Nat Photon 2013, 7, 634-638.

[7] J. Storch, J. Zadny, T. Strasak, M. Kubala, J. Sykora, M. Dusek, V. Cirkva, P. Matejka, M. Krbal, J. Vacek, Chemistry - A European Journal 2015, 21, 2343-2347.

[8] S. Sahasithiwat, T. Mophuang, L. Menbangpung, S. Kamtonwong, T. Sooksimuang, Synth. Met. 2010, 160, $1148-1152$.

[9] L. Shi, Z. Liu, G. Dong, L. Duan, Y. Qiu, J. Jia, W. Guo, D. Zhao, D. Cui, X. Tao, Chemistry - A European Journal 2012, 18, 8092-8099.

[10] T. Hatakeyama, S. Hashimoto, T. Oba, M. Nakamura, J. Am. Chem. Soc. 2012, 134, 19600-19603, pMID: 23167918.

[11] A. Wallabregue, P. Sherin, J. Guin, C. Besnard, E. Vauthey, J. Lacour, Eur. J. Org. Chem. 2014, 2014, 6431-6438.

[12] H. Oyama, K. Nakano, T. Harada, R. Kuroda, M. Naito, K. Nobusawa, K. Nozaki, Org. Lett. 2013, 15, 2104-2107.

[13] D. Schweinfurth, M. Zalibera, M. Kathan, C. Shen, M. Mazzolini, N. Trapp, J. Crassous, G. Gescheidt, F. Diederich, J. Am. Chem. Soc. 2014, 136, 13045-13052, pMID: 25154039.

[14] N. Saleh, B. Moore, M. Srebro, N. Vanthuyne, L. Toupet, J. A. G. Williams, C. Roussel, K. K. Deol, G. Muller, J. Autschbach, J. Crassous, Chem. Eur. J. 2015, 21, 1673-1681. 
[15] T. Suzuki, Y. Ishigaki, T. Iwai, H. Kawai, K. Fujiwara, H. Ikeda, Y. Kano, K. Mizuno, Chemistry-a European Journal 2009, 15, 9434-9441.

[16] J. Jacques, A. Collet, S. Wilen, 1981.

[17] S. Guy, A. Bensalah-Ledoux, A. Lambert, Y. Guillin, L. Guy, J. Mulatier, Thin Solid Films 2012, 520, 6440 - 6445.

[18] S. Guy, L. Guy, A. Bensalah, A. Pereira, V. Grenard, O. Cosso, T. Vautey, Journal of Material Chemistry 2009, 19, 7093-7097.

[19] L. Jierry, S. Harthong, C. Aronica, J.-C. Mulatier, L. Guy, S. Guy, Org. Lett. 2012, 14, 288-291.

[20] J. Mahieux, M. Sanselme, S. Harthong, C. Melan, C. Aronica, L. Guy, G. Coquerel, Crystal Growth \& Design 2013, 13, 3621-3631.

[21] S. K. De, R. A. Gibbs, Tetrahedron Lett. 2005, 46, 1647 - 1649.

[22] J. Wu, H.-G. Xia, K. Gao, Org. Biomol. Chem. 2006, 4, 126-129.

[23] B. Jiang, J.-j. Dong, Y. Jin, X.-1. Du, M. Xu, Eur. J. Org. Chem. 2008, 2008, 2693-2696.

[24] L. Li, D. Seidel, Org. Lett. 2010, 12, 5064-5067.

[25] R. Martinez, D. J. Ramón, M. Yus, The Journal of Organic Chemistry 2008, 73, 97789780, pMID: 18937410.

[26] F. Teplý, I. G. Stará, I. Starý, A. Kollárovič, D. Šaman, Š. Vyskočil, P. Fiedler, The Journal of Organic Chemistry 2003, 68, 5193-5197, pMID: 12816476.

[27] J. Autschbach, Chirality 2009, 21, E116-E152.

[28] J. Autschbach, L. Nitsch-Velasquez, M. Rudolph, Top. Curr. Chem. 2011, 298, 1-98.

[29] S. Graule, M. Rudolph, N. Vanthuyne, J. Autschbach, C. Roussel, J. Crassous, R. Reau, J. Am. Chem. Soc. 2009, 131, 3183-3185.

[30] L. Norel, M. Rudolph, N. Vanthuyne, J. G. Williams, C. Lescop, C. Roussel, J. Autschbach, J. Crassous, R. Reau, Angew. Chem. Int. Ed. 2010, 49, 99-102.

[31] E. Anger, M. Rudolph, C. Shen, N. Vanthuyne, L. Toupet, C. Roussel, J. Autschbach, J. Crassous, R. Reau, J. Am. Chem. Soc. 2011, 133, 3800-3803. 
[32] E. Anger, M. Srebro, N. Vanthuyne, L. Toupet, S. Rigaut, C. Roussel, J. Autschbach, J. Crassous, R. Reau, J. Am. Chem. Soc. 2012, 134, 15628-15631.

[33] C. Shen, E. Anger, M. Srebro, N. Vanthuyne, K. K. Deol, T. D. Jefferson, G. Muller, J. A. G. Williams, L. Toupet, C. Roussel, J. Autschbach, R. Réau, J. Crassous, Chem. Sci. 2014, 5, 1915-1927.

[34] N. Saleh, M. Srebro, T. Reynaldo, N. Vanthuyne, L. Toupet, V. Y. Chang, G. Muller, J. A. G. Williams, C. Roussel, J. Autschbach, J. Crassous, Chem. Commun. 2015, 51, 3754-3757.

[35] M. Srebro, N. Govind, W. de Jong, J. Autschbach, J. Phys. Chem. A 2011, 115, 1093010949.

[36] M. Srebro, J. Autschbach, J. Chem. Theory Comput. 2012, 8, 245-256.

[37] M. El Sayed Moussa, M. Srebro, E. Anger, N. Vanthuyne, C. Roussel, C. Lescop, J. Autschbach, J. Crassous, Chirality 2013, 25, 455-465.

[38] B. Moore, II, J. Autschbach, ChemistryOpen 2012, 1, 184-194.

[39] C. Shen, E. Anger, M. Srebro, N. Vanthuyne, L. Toupet, C. Roussel, J. Autschbach, R. Reau, J. Crassous, Chem. Eur. J. 2013, 19, 16722-16728.

[40] J. Autschbach, M. Srebro, Acc. Chem. Res. 2014, 47, 2592-2602.

[41] L. A. Nafie, 2011.

[42] L. A. Nafie, in Comprehensive Chiroptical Spectroscopy, volume 1, pp. 115-146, New York, 2012.

[43] L. D. Barron, Cambridge, UK, second edition, 2009.

[44] T. Bürgi, A. Urakawa, B. Behzadi, K.-H. Ernst, A. Baiker, New J. Chem. 2004, 28, 332334.

[45] S. Abbate, F. Lebon, G. Longhi, F. Fontana, T. Caronna, D. A. Lightner, Phys. Chem. Chem. Phys. 2009, 11, 9039-9043.

[46] S. Abbate, G. Longhi, F. Lebon, E. Castiglioni, S. Superchi, L. Pisani, F. Fontana, F. Torricelli, T. Caronna, C. Villani, R. Sabia, M. Tommasini, A. Lucotti, D. Mendola, A. Mele, D. A. Lightner, J. Phys. Chem. C 2014, 118, 1682-1695. 
[47] A. H. Pandith, N. Islam, Z. F. Syed, S. U. Rehman, S. Bandaru, A. Anoop, Chem. Phys. Lett. 2011, 516, 199-203.

[48] T. B. Freedman, X. Cao, A. Rajca, H. Wang, L. A. Nafie, J. Phys. Chem. A 2003, 107, 7692-7696.

[49] C. Herse, D. Bas, F. C. Krebs, T. Bürgi, J. Weber, T. Wesolowski, B. W. Laursen, J. Lacour, Angew. Chem. Int. Ed. 2003, 42, 3162-3166.

[50] P. Mobian, C. Nicolas, E. Francotte, T. Bürgi, J. Lacour, J. Am. Chem. Soc. 2008, 130, 6507-6514.

[51] F. Torricelli, J. Bosson, C. Besnard, M. Chekini, T. Bürgi, J. Lacour, Angew. Chem. Int. Ed. 2013, 52, 1796-1800.

[52] V. P. Nicu, J. Neugebauer, S. K. Wolff, E. J. Baerends, Theor. Chem. Acc. 2008, 119, 245-263.

[53] V. Liégeois, B. Champagne, J. Comp. Chem. 2009, 30, 1261-1278.

[54] J. Hrbac, J. Storch, V. Halouzka, V. Cirkva, P. Matejka, J. Vacek, RSC Adv. 2014, 4, $46102-46105$.

[55] N. Engheta, P. Pelet, Opt. Lett. 1989, 14(11), 593-5.

[56] R. Kuroda, T. Harada, Y. Shindo, Rev. Sci. Instrum. 2001, 72, 3802-3810.

[57] T. Buffeteau, F. Lagugne Labarthet, C. Sourisseau, Appl. Spectrosc. 2005, 59, 732-745.

[58] J. A. Schellman, Chem. Rev. 1975, 75, 323-331.

[59] D. Hadiouche, C. L. Luyer, L. guy, A. Bensalah-Ledoux, S. Saoudi, H. Khireddine, S. Guy, Optical Materials 2014, 36, 885-891. 